NBER WORKING PAPER SERIES

\title{
LEAD POLICY AND ACADEMIC PERFORMANCE: INSIGHTS FROM MASSACHUSETTS
}

\author{
Jessica Wolpaw Reyes \\ Working Paper 18327 \\ http://www.nber.org/papers/w18327
NATIONAL BUREAU OF ECONOMIC RESEARCH
1050 Massachusetts Avenue
Cambridge, MA 02138
August 2012

The author would like to thank many people for valuable advice and comments: Sarah Carleton, Carrie Conaway, Chris Foote, Paul Hunter, Jun Ishii, Robert Knorr, Yolanda Kodrzycki, Alicia Sasser Modestino, Sarah Neslund, René Reyes, Lisa Sanbonmatsu, Jeffrey Zabel, Bo Zhao, and seminar participants at the New England Public Policy Center, the Federal Reserve Bank of Boston, the Bureau of Environmental Health of the Massachusetts Department of Public Health, and the Healthy Homes Lead Poisoning Prevention Branch of The Centers for the Disease Control and Prevention. Research staff at the Massachusetts Department of Public Health and the Massachusetts Department of Elementary and Secondary Education provided invaluable support with data acquisition and processing. Christopher Morrison provided outstanding research assistance. Any remaining errors are the author's own. This research was generously supported by the New England Public Policy Center of the Federal Reserve Bank of Boston. The views expressed in this paper are those of the author and not necessarily those of the Federal Reserve System, the Federal Reserve Bank of Boston, or the National Bureau of Economic Research.

NBER working papers are circulated for discussion and comment purposes. They have not been peerreviewed or been subject to the review by the NBER Board of Directors that accompanies official NBER publications.

(C) 2012 by Jessica Wolpaw Reyes. All rights reserved. Short sections of text, not to exceed two paragraphs, may be quoted without explicit permission provided that full credit, including $\odot$ notice, is given to the source. 
Lead Policy and Academic Performance: Insights from Massachusetts

Jessica Wolpaw Reyes

NBER Working Paper No. 18327

August 2012

JEL No. I18,I29,J13,Q58

\begin{abstract}
$\underline{\text { ABSTRACT }}$
Childhood exposure to even low levels of lead can adversely affect neurodevelopment, behavior, and cognitive performance. This paper investigates the link between lead exposure and student achievement in Massachusetts. Panel data analysis is conducted at the school-cohort level for children born between 1991 and 2000 and attending 3rd and 4th grades between 2000 and 2009 at more than 1,000 public elementary schools in the state. Massachusetts is well-suited for this analysis both because it has been a leader in the reduction of childhood lead levels and also because it has mandated standardized achievement tests in public elementary schools for almost two decades. The paper finds that elevated levels of blood lead in early childhood adversely impact standardized test performance, even when controlling for community and school characteristics. The results imply that public health policy that reduced childhood lead levels in the 1990s was responsible for modest but statistically significant improvements in test performance in the 2000s, lowering the share of children scoring unsatisfactory on standardized tests by 1 to 2 percentage points. Public health policy targeting lead thus has clear potential to improve academic performance, with particular promise for children in low income communities.
\end{abstract}

Jessica Wolpaw Reyes

Department of Economics

Amherst College

Amherst, MA 01002

and NBER

jwreyes@amherst.edu 


\section{Introduction}

Children in modern society are exposed to numerous environmental toxins, and the effects of these toxins on psychological and cognitive development are plausibly substantial. This paper investigates one such pathway by which an environmental exposure may affect childhood development and academic performance. Using data from Massachusetts in the 1990s and 2000s, I investigate the link between lead exposure in early childhood and student test scores in the elementary school years. Massachusetts has been a leader in the prevention of childhood lead poisoning and the reduction of childhood lead exposure. While great strides have been made in reducing blood lead levels among children in the state, we do not have a good sense of how these improvements have benefitted society. This paper quantifies the societal impact of these reductions in childhood lead exposure.

There is strong evidence that lead exposure adversely affects children's development, and consequently that reducing children's lead exposure has substantial benefits. However, it has proven more difficult to characterize the significance of these impacts at the societal level: Exactly what effects does lead have at the societal level? Put bluntly, we know lead is bad, but what does lead policy accomplish, if anything? This paper aims to contribute to the literature by assessing whether and to what extent reductions in lead exposure have been responsible for improved academic performance of Massachusetts children. While this paper looks to the past for answers, this question is not merely of historical interest: children in many areas of the world, both in the United States and abroad, are still exposed to moderate and high levels of lead. ${ }^{1}$ In the Spring of 2012, motivated by clear evidence that low and moderate exposures can have substantial adverse effects and that a not insignificant number of children are so exposed, the U.S. Centers for Disease Control lowered the "level of concern" by half (from $10 \mathrm{mcg} / \mathrm{dl}$ to 5 $\mathrm{mcg} / \mathrm{dl})$. This is not an issue of the past, but one that is of active policy interest for the present and future.

${ }^{1}$ For discussion of the continuing impact of lead on U.S. children, see, Mielke, Gonzales, and Mielke (2011) and Mielke, Laidlaw, and Gonzales (2010). 
Understanding the impact of aggressive lead policy has potentially wider implications. If lead policy improves health and childhood outcomes in substantial ways, it becomes more than public health policy and broadens to serve as effective social policy. ${ }^{2}$ Issues of environmental justice are also in play - by understanding how environmental factors may be responsible for socioeconomic achievement gaps, we can gain insight into the ways public policy that reduces inequities in exposure may be able to narrow those achievement gaps. And, lastly, lead is not merely of domestic concern: for developing countries around the world, an appreciation for the importance of lead policy in improving outcomes can make the case for incorporating lead policy as a key element in efforts to improve educational outcomes.

Thus, by looking in detail at the societal level effects of Massachusetts' lead reduction policies, this paper aims to characterize the broad significance of aggressive lead policy. There are several reasons why Massachusetts is a good choice for this analysis. First, individual level lead data is available for nearly all children born in Massachusetts since the early 1990s. The Massachusetts Childhood Lead Poisoning Prevention Program (CLPPP) of the Massachusetts Department of Public Health manages an extensive monitoring program, screening 80-90\% of children under the age of 6 in the state. Second, individual level test score data is available for all children in public schools in Massachusetts since the year 2001. The Massachusetts Department of Elementary and Secondary Education (DOE) collects and disseminates data on performance on state standardized tests of children in public schools, comprising 95\% of schoolage children in the state. Third, strong and aggressively-implemented public health policy in Massachusetts has produced substantial reductions in lead exposure, providing variation that can be used to identify a relationship between lead exposure and academic performance. Fourth, with data on the approximately 700,000 children born between 1991 and 2000 and attending the approximately 1,200 public elementary schools in Massachusetts, this analysis has the potential to identify effects that might be elusive when using a smaller sample size or different research design.

\footnotetext{
${ }^{2}$ Anyon (2005) makes a similar argument that policymakers should think broadly and creatively about how policy can influence educational outcomes.
} 
However, it is important to acknowledge one significant limitation when using Massachusetts for this analysis: confidentiality restrictions prevent linking of the lead data to the test score data at the individual level. Instead, it is possible to link small groups of children (defined by school and birth year) and perform analysis relating various moments of the withingroup lead and test score distributions. As will be discussed in detail below, using moments of the distributions - rather than just means - takes some (but not all) of the sting out of this limitation.

Previewing the results, the paper provides support for the hypothesis that childhood lead exposure adversely affects academic performance. A preliminary investigation reveals a strong cross-sectional relationship between early childhood lead levels and elementary-school test scores. This is then confirmed with a differences-in-differences analysis: schools with bigger lead declines displayed larger performance improvements. The primary regression analysis is a panel data analysis on groups of children identified by school and birth year. When looking only at group means (a rough measure of group lead and performance), this analysis yields substantial but not robust results. When investigating other moments of the withingroup distributions, in particular the tails of the distributions, I find a significant and robust relationship between the share of children with high lead and the share of children with low test scores. Further analysis indicates that this result has potentially significant policy implications.

The paper proceeds as follows. Section II motivates the project and reviews the relevant literature on lead, educational outcomes, and public policy. Section III sets out a theoretical framework by which lead may affect academic performance. Section IV discusses and summarizes the data and Section V outlines the empirical approach that is employed to link childhood lead levels to educational outcomes. Section VI presents the empirical results, Section VII assesses their implications, and Section VIII concludes. 


\section{Background}

\subsection{Lead}

While lead is an extremely useful metal, it has also proved to be a dangerous toxin. Exposure to lead is particularly damaging for young children, who not only absorb lead more efficiently than adults but are also at a sensitive stage of their neurobehavioral development. ${ }^{3}$ Historically, the primary environmental sources of lead exposure for the average child have been lead-based paint, leaded gasoline, and lead water pipes. This paper studies effects of exposure to lead from any of these sources, although it is likely that most exposure in Massachusetts in the 1990s arose from exposure to deteriorating lead-based paint in older housing and deposition of lead in soil from leaded gasoline. With no leaded gasoline or leaded paint in general use since the mid 1980s, these were the primary dangers in the 1990s and 2000s. ${ }^{4}$

Lead was added to paint to improve its performance, both as a pigment and as a way to improve function, appearance, and durability. In the United States, lead levels in paint peaked in the early 1900s and declined smoothly from 1920 onwards, with breaks in 1950 when leadbased paint was banned for interior use and in 1978 when it was banned for all residential uses. With no lead paint currently in general residential use, the primary danger since the 1980s stems from older housing with deteriorating paint: children absorb lead from paint directly when they ingest paint chips or indirectly when they come in contact with lead dust from deteriorating paint.

Likewise, lead was added to gasoline to improve performance, specifically to reduce engine knock and increase octane and thereby engine power. In the United States, lead emissions from gasoline sources rose markedly from the 1920s through the 1960s, then declined drastically from 1974 to 1985 as a result of the Clean Air Act's mandate to remove lead from

${ }^{3}$ Hammond (1988) reports that children absorb up to $50 \%$ of lead they ingest, compared with $8 \%$ for adults. Bellinger (2004) reviews the differences in lead absorption between children and adults. ${ }^{4}$ See, e.g., Mielke, Gonzales, and Mielke (2011) and Mielke, Laidlaw, and Gonzales (2010). 
gasoline. ${ }^{5}$ With no leaded gasoline currently in general use, the primary danger since the mid 1980s stems from deposition in the soil: children can absorb lead indirectly from contact with lead deposits that accumulated in soil from vehicular traffic in the years prior to the removal of lead from gasoline. ${ }^{6}$

The importance of water mains and pipes as a source of lead exposure is becoming more evident, but there are few easily-observed changes and consequently diminished opportunities for identification of these effects. ${ }^{7}$

Whatever the source, exposure to lead results in the absorption of lead into the human body. A blood lead level (BLL), the measured used in this paper, is a good measure of recent and current exposure. It is the concentration of lead in blood circulating in the body, and is usually measured in micrograms of lead per deciliter of blood $(\mu \mathrm{g} / \mathrm{dL}) .{ }^{8}$ Since taking a blood sample is relatively simple, blood lead measures are the most commonly available. As discussed below, this investigation uses blood lead measures collected between 1990 and 2008 by the Massachusetts Department of Public Health for more than 800,000 children born in the 1990s.

${ }^{5}$ In 1974, under the authorization of the Clean Air Act, the EPA mandated a timetable for the reduction of lead in gasoline, requiring petroleum companies to meet certain targets of maximum grams of lead per gallon of gasoline. Ultimately, the phase-out was a success, and both gasoline lead emissions and blood lead levels declined drastically between 1975 and 1990. Between 1975 and 1990, all measures of lead exposure (on-road vehicle emissions, other emissions, air lead, gasoline lead, and blood lead) declined drastically and in concert with one another. Between 1975 and 1990, total lead emissions declined by 97\% and gasoline lead went from the dominant source of lead ( $80 \%$ of emissions) to a minor source ( $8 \%$ of emissions). (U.S. Environmental Protection Agency (1998).) The reduction in lead emissions was closely associated with corresponding large reductions in the blood lead levels of Americans in all demographic groups. The entire distribution shifted downward, and the national mean dropped from $16 \mu \mathrm{g} / \mathrm{dL}$ in 1976 to $3 \mu \mathrm{g} / \mathrm{dL}$ in 1991. Analysis on data from the National Health and Nutrition Examination Survey (NHANES); U.S. Environmental Protection Agency (1991); Brody, et al. (1994).

${ }^{6}$ During the years when gasoline contained high levels of lead, gasoline represented "the most ubiquitous source of lead found in the air, dust, and dirt in urban areas" (U.S. Environmental Protection Agency (1973).) During that time period, blood lead levels were highly correlated with recent gasoline lead consumption (Schwartz and Pitcher (1989)).

${ }^{7}$ For information on dangers from lead in water pipes and mains, see Troesken (2006).

${ }^{8}$ Dentine and bone lead levels reflect the concentration of lead in teeth and bone, respectively, and are regarded as good indicators of cumulative past exposure. 
Since blood lead levels are central to this analysis, it is important to understand their meaning and significance. Until recently, the Centers for Disease Control and Prevention (CDC) identified $10 \mu \mathrm{g} / \mathrm{dL}$ as the "level of concern" for children, indicating that levels below 10 $\mu \mathrm{g} / \mathrm{dL}$ should not arouse any concern for a child's health. However, with mounting evidence that lead is harmful even at lower levels, the CDC decided to lower this "level of concern" to 5 $\mu \mathrm{g} / \mathrm{dL} .{ }^{9} \quad$ At the same time, we should clarify the distinction between lead exposure and lead poisoning. Lead exposure is simply exposure to some level of lead, as indicated by a non-zero blood lead level. In contrast, lead poisoning encompasses a certain set of symptoms and occurs at particularly high levels of exposure (usually blood lead levels in excess of $20 \mu \mathrm{g} / \mathrm{dL}$ ), although this term is sometimes also applied to blood lead above the "level of concern." This paper is primarily concerned with investigating the broad effects of common but more moderate lead exposure, rather than the more focused effects of rare but severe lead poisoning.

\subsection{Academic Performance}

Characteristics such as the ability to learn well, to listen, to cooperate, and to be respectful of others are established early in life and are foundational elements of human capital. On the other hand, characteristics such as easy distractability, short temper, and reduced cognitive capacity may interfere with the development of human capital. Thus, investigating factors that influence development and cognitive performance early in life can help us understand how those factors, and policy intended to impact them, might affect the accumulation of human capital and with it later life social behavior and labor market performance.

Academic performance in childhood is therefore a useful place to start when understanding human capital accumulation. A growing body of literature makes the argument that labor economics and the economics of education should cast a wider lens by looking back at formative early life experiences and environments as determinants of later life outcomes. Almond and Currie (2010), for example, cite abundant results showing that events in early

${ }_{9}^{9}$ For example, see Bellinger (2008), Gilbert and Weiss (2006), and CDC (2010). Data from the National Health and Nutrition Examination Survey (NHANES) 1999-2002 indicate that at that time only 1.7\% of children in the United States exhibited blood lead levels above the $10 \mu \mathrm{g} / \mathrm{dL}$ "level of concern." 
childhood can have long-lasting impacts on adult outcomes, and argue that understanding such influences is an important piece of understanding adult behavior and outcomes. ${ }^{10}$

\subsection{Lead Exposure and Academic Performance}

Children are exposed to numerous environmental toxicants that may adversely affect their neurodevelopment, cognitive capacity, and behavior. Lead is one of these toxicants: it is a hazardous neurotoxicant with a wide range of adverse effects on human health and behavior. Extensive evidence indicates that childhood exposure to lead reduces intelligence quotient (IQ), impairs behavior, impairs academic performance, and increases learning disabilities. ${ }^{11}$

Moreover, these effects on children's cognitive performance are long-lasting; that is, exposure to lead in early childhood can affect cognitive performance later in childhood and beyond. Additionally, these effects on children's cognitive performance occur at very low levels of lead exposure. ${ }^{12}$ In contrast with the earlier belief that levels below $10 \mu \mathrm{g} / \mathrm{dL}$ were safe, mounting evidence indicates that any level of lead can be harmful. Reviewing the literature, Bellinger (2008) reports that lead levels below $10 \mu \mathrm{g} / \mathrm{dL}$ are associated with reduced IQ, academic deficits, and neuropsychiatric disorders, and that marginal effects may even be greater at the lowest lead levels. Bellinger concludes that "no level of lead exposure appears to be 'safe' and even the current 'low' levels of exposure in children are associated with neurodevelopmental deficits." Thus, while lead and academic performance are each of independent interest, the link between the two is plausibly strong, practically relevant, and certainly of interest.

\subsection{Lead Policy in Massachusetts}

Massachusetts has been at the forefront of the prevention of childhood lead poisoning and the reduction of childhood lead exposure. Since 1971, Massachusetts law has required the removal or covering of lead paint hazards in homes where any children under six reside and has mandated a program for the prevention, screening, diagnosis, and treatment of lead

\footnotetext{
10 See also Case and Paxson (2010).

${ }^{11}$ See, e.g., Lanphear et al (2005), Canfield et al (2003), Miranda et al (2009).

${ }^{12}$ Canfield et al (2003).
} 
poisoning. ${ }^{13}$ Massachusetts' lead laws are among the strongest and most comprehensive of the states, and the Massachusetts Childhood Lead Poisoning Prevention Program (CLPPP) is viewed as a pioneering program that has been effective in reducing lead poisoning and exposure. The CLPPP oversees the mandatory lead screening of all children under the age of 6 , the provision of appropriate medical and environmental services to affected individuals and their families, and the development and implementation of policies aimed at eliminating sources of lead exposure. To those ends, CLPPP also engages in a wide slate of research, educational, and clinical activities. These efforts in Massachusetts have been quite successful in substantially reducing lead levels and lead poisoning rates. As of 2010 , only $0.078 \%$ of screened Massachusetts children had lead levels above $20 \mu \mathrm{g} / \mathrm{dL}$.

\subsection{Education Policy in Massachusetts}

The Massachusetts Department of Elementary and Secondary Education oversees the public education system for Massachusetts. In any given year, approximately 1,200 elementary schools serve approximately 400,000 students in Kindergarten through Grade 6. These schools are distributed across the 351 municipalities of Massachusetts, and organized into approximately 300 local or regional school districts.

In 1993, the Massachusetts Education Reform Act (MERA) instituted fundamental changes to public education in Massachusetts. One element of MERA was a new framework allocating state aid as the difference between a foundation budget (a basic level required to fund an adequate education) and a community's ability to contribute its own funds. Downes, Zabel, and Ansel (2009) find that between 1993 and 2000 MERA significantly reduced funding gaps, thereby stemming increases in achievement gaps that would have occurred otherwise. ${ }^{14}$ However, they caution that MERA was not entirely successful reducing within-state inequality: large within-state disparities remain, associated with the increasing concentration of low-

${ }^{13}$ MA CLPPP Act of 1971 (MGLc.111, ss 189A-199B). Appendix A explains the relevant lead laws in Massachusetts in greater detail.

${ }^{14}$ This result for Massachusetts aligns with the more general conclusion of Card and Payne (2002) that equalization of education spending in various states reduced gaps in test scores. 
income and limited English proficiency students in certain localities and with an unchanged gap in spending between the top spending quartile and the other three spending quartiles. ${ }^{15}$

A second major component of MERA was the institution of the Massachusetts Comprehensive Assessment System (MCAS) tests. MCAS tests are administered each April for specific subjects in particular grades, and are required of all students educated in the public schools in Massachusetts. The goals of the MCAS are to monitor student, school, and district performance, and thereby to inform curricular and instructional policy. Appendix B explains the administration and scoring of the MCAS tests in greater detail.

Because MCAS testing was already in place, the federal No Child Left Behind Act of 2001 (NCLB) did not initiate a new testing framework, but rather expanded the existing framework of statewide testing in Massachusetts. NCLB requires states to administer assessments in basic skills and to use the results of those assessments to inform education reform; it also links federal funding to performance improvements. This framework is similar to what was already in place from MERA, though arguably more extensive and more burdensome in its link between scores and funding.

\subsection{Lead and Academic Performance in Massachusetts}

The established relationship between childhood lead exposure and adverse neurobehavioral effects renders it likely that the moderate to low levels of lead (below $15 \mu \mathrm{g} / \mathrm{dL}$ ) that were common in Massachusetts children born in the 1990s could plausibly have impaired cognitive performance of those children. In addition, public policy in Massachusetts greatly reduced lead levels of children in that time period. Consequently, it is reasonable to expect lead and lead policy to have had measurable effects on academic performance in Massachusetts as those children grew up. The plan for this analysis is to study the effects of early childhood lead on academic achievement of cohorts of children born in Massachusetts during the 1990s.

\footnotetext{
${ }^{15}$ For this analysis, it is important to note that nearly all of the impact of MERA on relative spending occurred in the 1990s, and so was complete by the 2000s (when this paper's analysis begins.)
} 


\section{Theory}

As just stated, the goal of this paper is to study a putative causal link between childhood lead exposure and impaired academic performance. While the details of the underlying physiological mechanism by which lead impairs cognitive function are beyond the scope of this paper, the broad outlines of that mechanism are reasonably simple and can be expressed within the framework of the standard economic model of behavior.

First, we write the performance outcome $P$ as a function of characteristics, environment, and inputs:

$$
P=p(A, B, X, F, C, S) .
$$

The variables $A$ and $B$ represent cognitive and behavioral ability, respectively. The variables $X$, $F, C$, and $S$ respectively represent vectors of individual, family, community, and school characteristics. It is assumed that these characteristics will have direct, indirect, and interactive effects on $P$. For example, a family characteristic such as poverty would enter directly as a family characteristic but might also influence community characteristics, school characteristics, or even ability itself. An environmental factor might play a similarly complex role in affecting performance.

Lead exposure is modeled as a function of family and community characteristics, and is also influenced by government policy $G$ and any protective behavior $H$ undertaken by the family:

$$
L=l(F, C, G, H) .
$$

Lead exposure would, in turn, affect both types of ability directly:

$$
A=a(L, X, F, C, S) \quad \text { and } \quad B=b(L, X, F, C, S) .
$$

The inclusion of the various characteristics indicates that those characteristics can modify both the lead level resulting from a given exposure and the effect of that lead level on ability. Ultimately, performance is a complicated function of characteristics, behaviors, and policies:

$$
\begin{aligned}
P \quad & =p(A, B, X, F, C, S) \\
& =p(a(L, X, F, C, S), b(L, X, F, C, S), X, F, C, S) \\
& =p(a(l(F, C, G, H), X, F, C, S), b(l(F, C, G, H), X, F, C, S), X, F, C, S) .
\end{aligned}
$$


Obviously the precise structure of these relationships is far too complex to be determined via a simplified reduced-form model of this type. However, we can state several simple qualitative hypotheses that are likely to be true:
$\mathrm{\partial} P / \mathrm{\partial} A>0 \quad$ Higher ability causes higher performance
$\mathrm{\partial} A / \partial L<0 \quad$ Higher lead level causes lower ability
$\partial P / \partial L<0 \quad$ Higher lead level causes lower performance
(follows via the chain rule from $\partial A / \partial L<0$ and $\partial P / \partial A<0$ ).
$\partial P / \partial G>0 \quad$ Government policy that reduces lead improves performance
(follows via the chain rule from $\partial L / \partial G<0$ and $\partial P / \partial L<0$ ).

The last two are the main hypotheses that will be tested by this paper. I ask whether higher lead impairs academic performance and whether government policy that reduces lead thereby improves academic performance.

We can also remark upon other characteristics of the performance function which are theoretically more ambiguous:

$$
\begin{array}{ll}
\partial^{2} P / \partial L^{2}>0 & \begin{array}{l}
\text { Marginal effect of lead declines with lead } \\
|\partial P / \partial L|_{\text {Dis }}>|\partial P / \partial L|_{\text {ADv }}
\end{array} \\
\begin{array}{l}
\text { Marginal effect of lead is larger for disadvantaged } \\
\text { children (due to interaction with other characteristics). }
\end{array}
\end{array}
$$

These characteristics would be suggested by the existing literature: a declining marginal effect of lead on IQ was established by Canfield et al (2003), the literature on self-protective behavior would indicate that lower income and otherwise disadvantaged families have fewer ways to reduce lead's effects and more factors that may exacerbate them.

The foregoing theory is written to describe the effects of an individual child's lead on that individual child's performance outcome. It is also possible that there may be spillover effects of lead through peer effects. One child's inattention or disruptive behavior can interfere with his classmates' learning or reduce his teacher's effectiveness. If lead reduces attentiveness or increases disruptive behavior, it could adversely affect the performance of other children in the same classroom. Such a pathway would serve to amplify any effects of lead. 


\section{Data}

\subsection{Data Structure}

The ideal data for this analysis would be comprised of individual-level observations that include lead level in early childhood, test scores in elementary school, and other individual, family, community, and school characteristics. However, at the present time data confidentiality restrictions have made it infeasible to link data on lead and test scores for each individual child. Instead, the data for this analysis is a panel comprised of groups of Massachusetts school children. This structure for the data creates a number of challenges that will be discussed below in Section 5.2.

The dataset will be constructed from data for all children born between 1991 and 2000 in Massachusetts and attending $3^{\text {rd }}$ and $4^{\text {th }}$ grades between 2000 and 2009 at public elementary schools in Massachusetts, and taking MCAS tests between April 2001 and April 2009. Each group of children is identified by the year in which the children were born and the elementary school the children attend. For example, one group might be children who were born in 1994 and attend Leverett Elementary: this group would attend $3^{\text {rd }}$ grade at Leverett Elementary in the school year 2002-2003 and take the $3^{\text {rd }}$ grade MCAS test towards the end of the school year in April 2003. For each group of children, elementary school academic achievement measures are constructed from MCAS data and early childhood lead levels are constructed from CLPPP data. The set of cohorts used in the analysis is described in Appendix Table 1.

\subsection{Lead Data}

Data on childhood lead levels come from the screening and monitoring program operated by the Massachusetts Childhood Lead Poisoning Prevention Program (CLPPP) of the Massachusetts Department of Public Health (DPH). As discussed above, Massachusetts law mandates lead screening of all children under the age of 6 . The blood lead levels measured by these mandatory screenings are entered into a database used by CLPPP to monitor lead levels and lead poisoning, and it is this database that is employed. 
A single child may be screened for lead multiple times in his or her young life - either in separate years or possibly multiple times in the same year. All of these measures are entered into the database, along with the geographic location of the child's residence, some limited details about the method of each lead screening (venous or capillary), and very limited and sparsely reported demographics. The dataset allows the linking over time of lead measurements for an individual child. Overall, of children attending public elementary school in Massachusetts, approximately $80-90 \%$ have at least one early childhood lead measure in the CLPPP database. ${ }^{16}$ To represent a child's early childhood lead level, I use the second highest lead measured for that child between the ages of 0 and 6 . Results are generally robust to alternate methods of measuring each child's lead level. ${ }^{17}$

Table 1 summarizes the data for the entire sample and for subsamples broken out by cohort (early vs. late) ${ }^{18}$ and income (bottom quartile or "low" vs. top quartile or "high"). ${ }^{19}$ We

${ }^{16}$ Note that this does not mean that $90 \%$ of children who later attend public school are screened for lead in every year, but rather that $90 \%$ of those children are screened at least once between the ages of 0 and 6 . CLPPP data indicates that approximately $50 \%$ of children age 0 to 6 are screened in any given year.

Compared to the full population of children in Massachusetts, between $80 \%$ and $90 \%$ are screened at some point between the ages of 0 and 6. For more detail, consult "Screening and Incidence Statistics by Community" produced by the CLPPP for fiscal years 1998 to 2010.

${ }^{17}$ There are several possible ways to calculate a representative lead measure for a child with more than one lead measurement. The CLPPP data provided to the author included one measure for each child in each year: the most reliable (based on screening method) and highest measure. Note that the number of measures for a child is endogenous: once a high lead measurement is found for a particular child, CLPPP offers the family treatment and services to lower the lead level and endeavors to re-test the child until the lead level drops to a safe level. Hence, averaging all lead measures for a particular child would bias the calculated lead level downward, particularly for children with high lead. As a way of avoiding both downward bias from averaging and upward bias from erroneously high measures, the analysis in this paper has been conducted using the second highest reliable measure available (as long as that is not also the lowest measure available; for children with two or fewer measures, the highest measure is used). It is important to note that the analysis and conclusions are robust to using the highest reliable measure available.

${ }^{18}$ Early cohorts are the 1991 and 1992 birth-year cohorts; late cohorts are the 1999 and 2000 birth-year cohorts. For 3rd grade test scores, the earliest cohort in the data is the 1992 cohort and the latest is the 2000 cohort. For 4th grade test scores, the earliest cohort in the data is the 1991 cohort and the latest is the 1999 cohort.

${ }_{19}$ Income categories are based on the town's (or city's) per-capita income in the year 2000. "Low Income" includes towns with income in the bottom quartile $(<\sim 20,000)$, "Middle Income" includes towns in the middle two quartiles $(\sim 20,000-30,000)$, and "High Income" includes towns in the top quartile $(>\sim 30,000)$. 
see that the average lead level in the sample was $4.2 \mu \mathrm{g} / \mathrm{dL}$, and that lead levels dropped substantially over the 1990s, falling from 5.2 to $3.1 \mu \mathrm{g} / \mathrm{dL}$. The table also shows that lead levels were significantly higher in low income towns relative to high income towns (5.4 vs. 4.1), but that this income-related gap closed somewhat over time (to 3.2 vs 2.2). Turning our attention to the share of children with elevated blood lead, we see a similar pattern but a more significant income gap and closing thereof. In the early cohorts, the average share with blood lead above $10 \mu \mathrm{g} / \mathrm{dL}$ was $11 \%$; for the late cohorts that drops to $3 \%$. This reduction is particularly intense in low income towns where the share drops from $12 \%$ to $3 \%$, compared with high income towns which saw a decline from $5 \%$ to $1 \%$.

To get a better sense of these temporal movements, Figure 1a displays the rate of elevated BLL (above $10 \mu \mathrm{g} / \mathrm{dL}$ ) for cohorts born in the years 1990 to 2008 . The figure shows that the share of children with lead levels above $10 \mu \mathrm{g} / \mathrm{dL}$ declined significantly in the 1990s and more modestly in the subsequent decade. For children born in 1991, 7\% had lead levels exceeding $10 \mu \mathrm{g} / \mathrm{dL}$; that share drops to 1\% for the 2000 birth cohort and $0.3 \%$ for the 2008 birth cohort. Figure $1 \mathrm{~b}$ shows similarly striking declines in the share of children with lead levels above $5 \mu \mathrm{g} / \mathrm{dL}$, from more than one third of the 1991 birth cohort to approximately onetwentieth of the 2008 birth cohort. What is also evident is that lower income communities started the 1990s with much higher rates of elevated blood lead, but that this gap closed substantially over time. In other words, lead went down across the board, but even moreso for low income children.

\subsection{Test Score Data}

Data on academic achievement come from the Massachusetts Comprehensive Assessment System (MCAS) tests administered by the Massachusetts Department of Elementary and Secondary Education (DOE). As discussed above, Massachusetts and Federal laws mandate regular standardized testing of all children in public schools in the Commonwealth. The MCAS scores from these tests are entered into a database used by DOE to monitor student, school, and

These cutoffs are very close to the actual quartile cutoffs, and hence are employed as convenient markers for cutting the sample into subsamples. 
district performance. While limited demographics are provided with publicly-available statewide MCAS score summaries, they are not provided with the individual-level MCAS score data that is broken out by school and used in this paper.

The test scores used in this analysis are the third and fourth grade MCAS scores for English Language Arts and Mathematics. ${ }^{20}$ These scores are available for the test years 2001 to 2009, except the $3^{\text {rd }}$ grade Math scores which are not available for 2001 to 2005 . Numeric scores are reported as the number of items answered correctly, and these are rescaled to the percentage correct (simply by dividing by the total number of items on the test). Numeric scores are also translated into qualitative categories of "Advanced"/“Above Proficient," "Proficient," “Needs Improvement," and "Warning"/“Failing."21 Scoring "Proficient" or above is deemed "satisfactory" by the DOE; scoring "Needs Improvement" or below is deemed "unsatisfactory." Both the quantitative (percent correct) and qualitative (categorical) measures will be used in this paper.

Table 1 summarizes the $3^{\text {rd }}$ and $4^{\text {th }}$ grade MCAS scores for the sample period. The average percentage correct hovers around two-thirds to three-quarters: $76 \%$ for $3^{\text {rd }}$ grade English, $75 \%$ for $3^{\text {rd }}$ grade Math, $70 \%$ for $4^{\text {th }}$ grade English, and $66 \%$ for $4^{\text {th }}$ grade Math. The average share scoring satisfactory is relatively low, ranging from $37 \%$ to $64 \%$ depending on the grade and subject. The table also shows large and persistent income gaps in performance: the satisfactory rate is approximately 30 percentage points lower in low income towns, and this gap persists to the end of the sample period. For example, while $71 \%$ of $4^{\text {th }}$ graders in the early cohorts in high income towns display satisfactory performance in English, only $36 \%$ of $4^{\text {th }}$ graders in low income towns do so; the gap is almost identical for the late cohorts. Considering trends over the sample period, we see that $3^{\text {rd }}$ grade English scores declined, $4^{\text {th }}$ grade English scores held steady, and $4^{\text {th }}$ grade Math scores improved. These changes had little effect on income gaps, however, with only the $4^{\text {th }}$ grade Math gap closing slightly, by 3 percentage points in the percent correct and 4 percentage points in the share scoring satisfactory. However,

${ }^{20}$ For convenience, this paper will refer to English Language Arts scores as "English" scores and Mathematics scores as "Math" scores.

${ }^{21}$ Massachusetts Department of Elementary and Secondary Education, "Massachusetts Comprehensive Assessment System Overview," available at http://www.doe.mass.edu/mcas/overview.html. 
because the MCAS tests and their scoring may be modified from time to time, we must be cautious about concluding too much from time trends.

\subsection{Community and School Data}

Data on the characteristics of communities and schools are drawn from various sources. Massachusetts contains 351 municipalities (towns or cities), and these are assumed to represent the "community" in which the school is located and the child lives. Characteristics of municipalities include population density, poverty rate, per-capita income and its square, share of adults with less than a high school education, and share of adults with a bachelor's degree or beyond. Data on population, population density, and educational attainment are from the Decennial U.S. Census for the year 2000 and subsequent estimates created by the U.S. Bureau of the Census for the years 2001-2009. Data on income are from the Massachusetts Department of Revenue..$^{22}$

Characteristics of schools and school districts include school spending per pupil, the share of students who are low income, and the shares of students that are Black or Hispanic. These data are from the Massachusetts DOE, which uses school and district reporting, together with analysis of Census data, to create these measures by school and/or school district.

Table 1 summarizes these variables. We see that these characteristics of towns and schools showed much less movement over time than either lead or test scores. The most notable exceptions are the relative increases in the shares of low-income and Hispanic students in schools located in low-income municipalities, as discussed in Downes, Zabel, and Ansel (2009).

\section{Empirical Approach}

\subsection{Empirical Strategy}

The central empirical strategy of this paper is to use regression analysis to link blood lead levels in early childhood to educational outcomes in the elementary school years. As described above,

\footnotetext{
${ }^{22}$ All dollar values are adjusted for inflation by the CPI-U into year-2000 dollars.
} 
this analysis is performed on cohorts of Massachusetts schoolchildren, where each observation is a group of children identified by the elementary school the children attend and by the year in which the children were born. Panel data analysis is conducted for cohorts of children born between 1991 and 2000 and attending $3^{\text {rd }}$ and $4^{\text {th }}$ grades between 2000 and 2009 at the more than 1,000 public elementary schools in the Massachusetts. The idea is to assess the impact of Massachusetts' lead policy, and the effect of lead on academic performance, by investigating the relationship between lead and achievement for the cohorts most affected by the policy.

The primary regression equation is

$$
\text { MCAS Score } g(s, b) y=\alpha_{0}+\alpha_{1} \text { Lead Level }_{g(s, b)}+\boldsymbol{C}_{c(s) y} \boldsymbol{\beta}_{1}+\boldsymbol{S}_{s y} \boldsymbol{\beta}_{2}+\gamma_{y}+\varepsilon_{g(c, b) y}
$$

where the subscripts represent group $g$, school $s$, community $c$, birth year $b$, and year of MCAS test $y$. Note that the group $g$ is defined by the school $s$ and the birth year $b$, and hence is denoted $g(s, b)$. Similarly, the community $c$ is the community in which the school is located and is denoted $c(s)$. The variable MCAS Score represents a measure of the group's MCAS performance, either the group's average percentage correct or the share of the group achieving a certain qualitative performance standard (such as "satisfactory"). The variable Lead Level represents a measure of the group's childhood lead levels, either the average of the individual lead levels or the share of the group with lead levels in a certain range (such as above $10 \mu \mathrm{g} / \mathrm{dL}$ ). The coefficient $\alpha_{1}$ indicates the effect of lead on achievement, and hence is the main coefficient of interest. The vector $C$ is a set of community characteristics: population density, poverty rate, per-capita income and its square, share of adults in the town with less than a high school education, and share of adults in the town with a bachelor's degree or beyond. The vector $S$ is a set of school- or district-level characteristics: school spending per pupil in the district, share of students at the school who are low income, and the shares of students that are Black or Hispanic. Fixed effects for year are included as $\gamma_{y}$ to account for statewide time trends. When both grade-levels are pooled into a single regression, a dummy variable for fourth grade is also included in order to allow for different scoring and/or performance in the two grades. The regression is run as ordinary least squares, with weights representing group size (to reflect the number of individual children reflected in a group's observation) and Huber-White robust standard errors clustered on school. Because of the inclusion of controls and fixed effects, 
identification derives primarily from the variation in lead and test scores within each school over time.

\subsection{Challenges of Group-Level Analysis}

Although, by necessity, this paper uses groups of children as the level of observation, it is instructive to consider what an analysis would look like if it were performed using individual children as the level of observation as would usually be the case. In an individual-level analysis, the regression equation would be

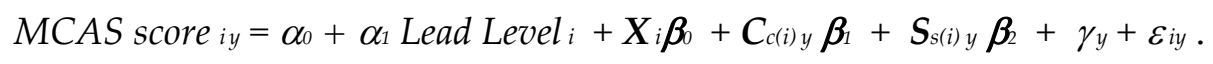

The subscripts represent individual $i$, school $s$, community $c$, and year of MCAS test $y$. The variable MCAS Score is a measure of the individual's MCAS performance, either the percentage correct or an indicator of whether the individual achieved a certain qualitative performance standard (in which case a probit would be employed). The variable Lead Level is a measure of the individual's childhood lead level. The vectors $C, S$, and $X$ include community, school, and individual characteristics. In equation 6 , as in equation 5, the coefficient $\alpha_{1}$ indicates the effect of lead on performance. Given the evidence indicating nonlinear effects of lead, it would be advisable to test other functional forms such as log, spline, or quadratic; with individual-level data (with individual-linked lead and performance), such tests would be possible. The estimated elasticity of performance with respect to lead could be calculated in the standard manner.

The question then becomes how to move between individual-level and group-level analyses. A number of papers address this question of inferring individual-level relationships when only group-level data is available. Firebaugh (1978) shows that the group-level coefficient will be unbiased relative to the individual-level coefficient only when the group average independent variable does not directly affect the group average dependent variable. However, with the possibility of peer effects by which group lead may affect individual test scores, the latter is likely not true in the present case. More recently, a number of authors have presented a variety of creative approaches to these issues, highlighting the complexity of the econometrics, 
the necessity for care in estimation, and the possibilities for bias when moving between group and individual analyses. ${ }^{23}$

For this particular situation, comparing the estimation procedure, coefficients, and elasticities for the individual-level analysis to those of the group-level analysis can shed some light on the challenges of this group-level analysis. First, there is less variation with which to identify the coefficient of interest. Group means by definition are less variable than individual values, and high or low values will be "smoothed out" by the averaging. With less useful variation, there will be a lower signal-to-noise ratio and possibly attenuation bias. ${ }^{24}$ Second, to the extent that the more important effects are among those with high lead and low scores, this averaging will bias elasticity estimates downward. This occurs because the ratio of Lead to MCAS (the factor by which the coefficient is multiplied to get an elasticity) is smaller for the group $\left(\overline{\text { Lead }}_{g} / \overline{M C A S}_{g}\right)$ than for the individual (Lead ${ }_{i} /$ MCAS $\left._{i}\right) .{ }^{25}$ Third, to the extent that the effects of lead vary with lead level, averaging will make it difficult to identify those changes in marginal effects. Group means will rarely show a mean lead of $15 \mu \mathrm{g} / \mathrm{dL}$ or a mean MCAS score of $30 \%$ correct, but this may be where the relationship is strongest. With "observations" pulled towards the middle of the distributions, the tails are unreachable by analysis.

There are, however, ways to address these issues. The most obvious solution to the first and third issues, short of using individual-level data, is to use other moments of the lead and test score distributions: medians, percentiles, or shares of the group above or below certain thresholds for lead and test scores. This would make better use of the within-group variation and distributions of both lead and test scores, positioning the analysis more effectively between the infeasible but detailed individual level analysis and the feasible but overly simplified group

\footnotetext{
${ }^{23}$ For example, see Berhane et al (2004).

${ }^{24}$ One way to understand this is to consider a mean-preserving spread of the Lead and MCAS distributions. Such a transformation would provide no new useful information in a regression of group means on group means. However, if indeed Lead and MCAS exhibit a significant covariance, such a transformation could provide substantial new useful information in a regression of individual values on individual values. This follows as a direct consequence of the fact that the regression coefficient is the ratio of the sample covariance of Lead and MCAS to the sample variance of Lead. The covariances and variances of group means are necessarily smaller, reducing the valuable signal for identifying a regression coefficient.

${ }^{25}$ Elasticities are defined as $\varepsilon_{\mathrm{Y} \text { rt } \mathrm{X}}=\% \Delta \mathrm{Y} / \% \Delta \mathrm{X}=(\Delta \mathrm{Y} / \Delta \mathrm{X}) \times(\mathrm{X} / \mathrm{Y})=\alpha_{1} \times(\mathrm{X} / \mathrm{Y})$.
} 
mean analysis. Thus, if a higher share of children in a group has lead above the "level of concern" of $10 \mu \mathrm{g} / \mathrm{dL}$, perhaps a higher share of children in that group will have test scores that are below the "satisfactory" level defined by the DOE. This still leaves a lower signal-to-noise ratio and possible attenuation bias if most of the action is happening in only a small portion of the sample population near the tails, but it gets closer to matching the empirical reality.

A solution to the second issue is to be careful when interpreting coefficients and calculating elasticities, so that we do not mistakenly elide the distinctions between group- and individual-level analyses. The implied effect of an individual's lead on that individual's performance is not necessarily equal to the estimated effect of a group's average lead on that group's average performance. We are well aware that elasticity of $y$ with respect to $x$ varies along a straight line - at any point the elasticity is calculated as the slope of the line times the ratio of $x$ to $y$. For an individual with above-average lead and below-average performance, the ratio of lead to performance is larger than the ratio of group average lead to group average performance; it follows that the coefficient needs to be scaled up by a larger factor in order to get the appropriate elasticity. For example, for a child with lead of $15 \mu \mathrm{g} / \mathrm{dL}$ and MCAS score of $40 \%$ correct in a group whose mean lead is $6 \mu \mathrm{g} / \mathrm{dL}$ and mean MCAS score is $70 \%$, the ratio for the individual is 4-5 times higher than the ratio of group averages. If indeed the analyses of shares described in the previous paragraph suggest that the action is at these high-lead/lowperformance locations, then estimated elasticities should be calculated with the appropriate adjustments. Alternately, we can use methods other than elasticity calculations to assess the practical significance of the effects.

These strategies may be at least partially effective in addressing the shortcomings of the group-level analysis, but we should not rush to the conclusion that they solve all of the problems. It remains the case that this analysis will depend on movements in distributions over time. After controlling for community and school characteristics, there will most certainly be much less movement in distributions of lead and scores than there would be in individual values. The analysis will endeavor to make the best possible use of these movements, but we should be cognizant of the fact that estimated coefficients may be substantially attenuated. 


\subsection{Other Empirical Issues}

Several other empirical issues merit attention. Because the analysis uses groups without being able to link the individuals, issues arise in the process of assigning individuals to groups. First, the town of residence for a child in the lead data is set equal to the most recent town of residence in the lead data. Second, the school for that child is determined from DOE data on what schools draw students from what towns, and what towns send students to what schools. ${ }^{26}$ If a child could attend several different schools, his or her lead data is included in all possible schools. ${ }^{27}$ Third, the birth date for a child is compared with the kindergarten entry dates for the appropriate school districts to determine the appropriate school cohort for the child. Most schools allow children to enter Kindergarten if they are 5 by September $1^{\text {st }}$, but some set this date later in the fall.

The above procedures necessarily result in some misallocation. Children who switch towns in the years between the time of their last lead test and third grade will be misallocated. Children who attend private schools or charter schools are in the lead data but not in the MCAS data, but we can't tell who those children are so they cannot be excluded from the lead data. Children who do not continue to attend school with their birth cohort, either by starting late or skipping a grade, will be misallocated. Children who leave the state altogether will be in the lead data but not in the MCAS data, and children who move to the state after age 6 may be in the MCAS data but not in the lead data. It is difficult to assess or correct for these assignment issues, but the available evidence suggests that each of these reasons for misallocation would pertain to less than $5 \%$ of children in the sample. Overall, since the misalloaction is not systematic in a direction that would bias our results upward, the most likely effect would be some attenuation of estimated effects.

Lastly, the use of group data raises the question of whether and how to weight the observations in a regression. The "group size" is an obvious choice, so I use the average of the

${ }^{26}$ The boundaries of towns and municipalities are generally coincident with the boundaries of school districts, and the DOE maintains detailed records on adjustments to school assignments. Consequently, this matching is relatively straightforward at the elementary-school level.

${ }^{27}$ Charter schools are excluded from the MCAS data because they draw students from wide and varying geographic areas. 
MCAS group size and the lead group size. In this way, the weights represent the number of children whose data went into the creation of the group distribution. I exclude groups if fewer than 10 children are present in either the MCAS group or the lead group, and cap the weight at a maximum of 100 children to avoid giving undue weight to exceptionally large schools, towns, or cities. ${ }^{28}$

\section{Results}

Before embarking on the regression analysis just described, it is worthwhile to take a preliminary look at the covariation between MCAS test scores and childhood lead levels in the cross-section, and also the co-movement of MCAS tests scores and childhood lead levels (using a differences-in-differences analysis). Section 6.1 does the former, and Section 6.2 does the latter. In Sections 6.3, 6.4, and 6.5 we turn to the full group-level regression analysis.

\subsection{Cross-Sectional Variation}

We first consider covariation between MCAS test scores and childhood lead levels. Figure 2 graphs the group average fourth grade MCAS score (percent correct) against the group average childhood lead level $(\mu \mathrm{g} / \mathrm{dL})$ for all of the groups in the sample at the beginning (born in 1992, in $4^{\text {th }}$ grade in 2001-2002) and end (born in 1999, in $4^{\text {th }}$ grade in 2008-2009) of the sample period. From this first look, it is clear that higher lead levels are associated with lower test scores. It is also apparent that this effect is stronger for Math than for English, and that it is stronger in the early cohort than in the later cohort. Lastly, we see that, as lead levels declined, test scores also rose, and that the entire distribution moved towards markedly lower lead and somewhat higher scores. The nature of this relationship, and whether this is in fact causal, remains to be determined.

${ }^{28}$ If weights were not capped, the empirical results would be dominated by high-population areas like Worcester, Springfield, or Boston. Analysis of group sizes leads to the selection of 100 as a reasonable cap that allows appropriately balanced representation of cities and towns in Massachusetts. 


\subsection{Differences in Differences}

One way to understand the variation in lead and test scores across communities and over time is to use a differences-in-differences analysis. Such an analysis compares how MCAS outcomes changed differentially over time in schools that experienced larger changes in lead levels as compared with schools that experienced smaller changes in lead levels. If lead does reduce academic performance, then we would expect the schools that experienced larger lead changes in early childhood in the 1990s to show relatively larger increases (or smaller declines) in academic performance in elementary schools in the subsequent decade.

To do this comparison, I include only schools for which MCAS data are available at both the start (2002) and end (2009) of the sample (this leaves 898 schools). I calculate the "lead change" for each school as the change, from the early cohort (born in 1992) to the late cohort (born in 1999), in the share of children with lead above $10 \mu \mathrm{g} / \mathrm{dL}$. The mean "lead change" in this time period is a decline of 0.044 , or 4.4 percentage points fewer children with lead above 10 $\mu \mathrm{g} / \mathrm{dL}$. Schools are classified as "high lead change" (treatment) or "low lead change" (control) based on the size of their lead decline. This classification is done in two ways. The first classification, shown in DD1, classifies schools as "high lead change" if their decline was larger than the mean decline and "low lead change" if their decline was smaller than the mean decline. The second classification, shown in DD2, classifies schools as "high lead change" if their decline was in the top quartile of declines (down more than 0.086) and "low lead change" if their decline was in the bottom quartile of declines (down less than 0.027)..$^{29}$

Table 2 shows the differences-in-differences for various combinations of grade, subject, and outcome measure (the individual difference-in-difference tables are not shown). We see that schools experiencing relatively larger lead declines exhibited relatively larger increases in mean percent correct score on the MCAS. These schools also exhibited relatively larger decreases in the share scoring unsatisfactory on the MCAS. The estimated differences-indifferences are right-signed in all cases and significant in most cases. Furthermore, the

${ }^{29}$ The average changes in share of children with blood lead above $10 \mu \mathrm{g} / \mathrm{dL}$ in the treatment and control groups were: -0.089 for treatment group $1,-0.025$ for control group $1 ;-0.126$ for treatment group $2,-0.013$ for control group 2. 
differences-in-differences are larger and more significant when comparing the top quartile to the bottom quartile (DD2) than when comparing the top half to the bottom half $(D D 1)$, as one would expect. For example, the share of children scoring unsatisfactory on the $4^{\text {th }}$ grade Math MCAS declined by 4.7 percentage points more in schools with above-average lead declines (relative to schools with below-average lead declines), and 6.5 percentage points more in schools with top-quartile lead declines (relative to schools with bottom-quartile lead declines.) Overall, this differences-in-differences analysis provides some support for the hypothesis that early childhood lead adversely affects academic performance on standardized tests. For the most part, schools whose student population experienced larger decreases in lead exposure in the 1990s appear to have experienced larger increases in MCAS scores in the 2000s.

\subsection{Regression of Average Test Scores on Average Lead}

I now turn to panel regression analysis on various moments of the within group-distributions. Our earlier discussion of group-level analysis makes the point that we very well may not find substantial relationships between group means (average lead and average test scores); we understand that much of the action may take place at the tails (high lead and low test scores). However, it still seems reasonable to begin the regression analysis by investigating the relationship between a group's average lead and that group's average test scores. Tables 3 and 4 do this. Both tables show highly significant coefficients on lead in all specifications except the fully controlled specification. In Table 3, we see that, in the baseline unweighted regression with no controls, the mean lead for the group has a statistically significant effect of -0.0258 on the mean test score for the group. This means that an increase of $1.0 \mu \mathrm{g} / \mathrm{dL}$ in average blood lead for a group is associated with a decline of 2.6 percentage points in the average percentage answered correctly by the group on the English MCAS. This effect is unchanged by the inclusion of weights for group size, and is doubled when year fixed effects are included. The coefficient is diminished by approximately a factor of 5 with the inclusion of either town or school characteristics, and drops drastically to an insignificant -0.0012 with the inclusion of both sets of characteristics. 
The coefficients for the control variables are generally of the expected sign, with population density, poverty, and share low income students decreasing test scores, and town income per capita, educational attainment, and school expenditures increasing test scores. Some of these signs are reversed in the full specification, but further investigation indicates that this is due to multicollinearity between particular variables (i.e. town income and school expenditures, and town poverty rate and school share low income students).

Tables 4 shows the corresponding results for a group's average lead and that group's average Math test scores. The Math results are qualitatively similar to the English results, although the uncontrolled specification yields a coefficient on lead more than twice as large. In this case, an increase of $1.0 \mu \mathrm{g} / \mathrm{dL}$ in average blood lead is associated with a decline of 6.1 percentage points in average percentage correct on the Math MCAS. After including year fixed effects and all of the control variables, the coefficient is reduced to a statistically insignificant 0.0013, almost identical to that for the English scores.

\subsection{Relationships between Other Moments of the Distributions}

The literature would suggest that lead's effects are non-linear and also likely to be modified by other factors. As discussed above, because data confidentiality restrictions require that the present analysis be conducted at the group level, this analysis cannot precisely account for those factors at the individual level. However, beyond just using group means, the within-group detail makes it possible to ascertain whether there are significant relationships between other moments of the two distributions. To do this, Table 5 investigates the relationship between the share of a group with elevated blood lead levels and the share of that group scoring unsatisfactory on the MCAS. The table shows results from three different sets of regressions run for English and Math, using different lead variables: set A uses share with lead above 10 $\mu \mathrm{g} / \mathrm{dL}$, set $\mathrm{B}$ uses share with lead above $20 \mu \mathrm{g} / \mathrm{dL}$, and set $\mathrm{C}$ uses both the share with lead between 10 and $20 \mu \mathrm{g} / \mathrm{dL}$ and share with lead above $20 \mu \mathrm{g} / \mathrm{dL}$ simultaneously. Only the coefficients on the lead variables are shown in the table.

In nearly all specifications, the share of a group with elevated blood lead has a statistically significant positive effect on the share of that group scoring unsatisfactory on the 
MCAS in both subjects. The specifications that do not control for town or school characteristics yield large effects: a 1 percentage point increase in the share with lead above $10 \mu \mathrm{g} / \mathrm{dL}$ is associated with a 2 to 4 percentage point increase in the share scoring unsatisfactory on the MCAS, while a 1 percentage point increase in the share with lead above $20 \mu \mathrm{g} / \mathrm{dL}$ is associated with 10 to 18 percentage point increase in the share scoring unsatisfactory. These effects decline substantially with the inclusion of control variables, but remain significant and do not disappear. In the fully controlled specification, a 1 percentage point increase in the share with lead above $10 \mu \mathrm{g} / \mathrm{dL}$ is associated with an increase of 0.2 percentage points in the share of that group scoring unsatisfactory. For higher lead levels, the effects are larger: a 1 percentage point increase in the share with lead above $20 \mu \mathrm{g} / \mathrm{dL}$ is associated with a 1 percentage point increase in the share of that group scoring unsatisfactory. Put another way: in a group of 100 children, the movement of 1 child's lead level past the $20 \mu \mathrm{g} / \mathrm{dL}$ mark causes 1 child's performance level to fall below the satisfactory mark. Of course, in the group analysis we cannot say whether this is the same child. However, assuming no spillover effects, this one-to-one result seems reasonable: one child experiences a higher lead level, and one child does poorly on the MCAS test. This also suggests that the town and school characteristics may effectively address the upward bias caused by cross-sectional variation in lead and scores, yielding a believable coefficient in the final fully-controlled specification.

The final rows of Table 5 show results from a variant of a spline, in which both the share of the group with lead between 10 and $20 \mu \mathrm{g} / \mathrm{dL}$ and the share of the group with lead above 20 $\mu \mathrm{g} / \mathrm{dL}$ are used in the same regression as measures of the group's lead. This analysis confirms that any lead above $10 \mu \mathrm{g} / \mathrm{dL}$ reduces test scores and that lead above $20 \mu \mathrm{g} / \mathrm{dL}$ is more detrimental to scores. Note that it does not imply that the marginal effect of lead is increasing with lead (in fact it appears to be declining), but rather that the total effect of lead is increasing with lead. If the lead level for 10 children in a group of 100 goes above $10 \mu \mathrm{g} / \mathrm{dL}$, approximately 2 children's scores will slip below satisfactory; if the lead level for those 10 children goes above $20 \mu \mathrm{g} / \mathrm{dL}, 4$ more children's scores will fall below that mark. 


\subsection{The Role of Income}

As already discussed, low-income children consistently exhibit higher childhood lead levels; in the current data the correlation between town per-capita income and the share of children with elevated blood lead is -0.31 . While the inclusion of town per-capita income, its square, and other control variables addresses this concern to some extent, it might be desirable to investigate the role of income further. Table 6 facilitates such an assessment, showing results from regressions of the share scoring unsatisfactory on the share with lead above $10 \mu \mathrm{g} / \mathrm{dL}$, but allowing the coefficient on the lead variable to vary by town income category (low, medium, and high as defined earlier). This allows us to assess to what extent estimated effects of lead are driven by cross-sectional income differences, whether lead has a significant effect on scores within income categories, and whether the effect of lead varies by income category.

Table 6 provides strong support for a relationship between lead and test scores that is not driven by income alone, but also provides new information about the role income does play. For English scores, the uncontrolled specification yields significant effects of lead in all three income categories. The first piece of news here is that the amplification of the effect in the uncontrolled specification (seen in Table 5) is not driven by variation within the high income towns: in column 1, the interaction of lead with high income (0.58) is statistically significant but much smaller than the interactions of lead with the other income categories (3.54 and 3.68 respectively). The second piece of news is that lead is not merely proxying for income: with the introduction of town and school characteristics as controls, the effect of lead is statistically significant for all three income categories, and larger in the middle- and high-income towns. In those towns, a 1 percentage point increase in the share with elevated blood lead is associated with a 0.4 percentage point increase in the share scoring unsatisfactory, an effect twice as large as that estimated when the lead coefficients were restricted to be equal across income categories (as in Table 5).

For Math scores, the uncontrolled specification yields significant effects of lead in only the low- and middle-income categories. With the introduction of town and school characteristics, we see that the effect of lead on Math scores is driven entirely by the middleincome towns. In those towns, a 1 percentage point increase in the share with elevated blood 
lead is associated with a 0.5 percentage point increase in the share scoring unsatisfactory, an effect more than twice as large as that estimated when the lead coefficients were restricted to be equal across income categories. It is worth recalling that $3^{\text {rd }}$ grade Math MCAS tests were not administered in the years 2001 to 2005 , so the number of observations is about $25 \%$ smaller for Math than for English.

In the end, we can conclude from Table 6 that the effects of elevated blood lead on unsatisfactory performance shown in Table 5 are not entirely driven by cross-sectional income differences. The effects are, to a great degree, still apparent within income categories. The results are not unaffected, however. Lead's effects on English scores are significant and sizable within all three income categories, but larger in the middle- and high-income categories. Lead's effects on Math scores are significant only within the middle income category, and it appears the Math results are largely driven by the variation within this one category.

\section{Implications}

In the 1990s, public health policy achieved large reductions in the childhood lead levels of Massachusetts children. Having established a relationship between lead and academic performance, we are now in a position to assess the full impact this lead reduction may have had on academic performance. When doing so, it is important to acknowledge that the foregoing analyses are not able to establish causality beyond any doubt, and consequently these assessments will necessarily push the paper's results at least slightly beyond the empirical domain in which they were established. With this in mind, we can consider several ways to assess the impacts of lead policy.

Applying the main results from Section 6.4, the 8.2 percentage point decline in the share of Massachusetts children with blood lead above $10 \mu \mathrm{g} / \mathrm{dL}$ would produce a decline of 1.7 percentage points in the share of children scoring unsatisfactory on the MCAS. ${ }^{30}$ This improvement, when compared to the base rate of 30-35 percent of children scoring

${ }^{30}$ Coefficients are from the fully controlled regressions of share scoring unsatisfactory on share with blood lead above $10 \mu \mathrm{g} / \mathrm{dL}$, as shown in Table 5 and Appendix Tables 2 and 3. Because the coefficients on lead are nearly identical between the English and Math regressions, values quoted in the text are based on the average of the two for convenience. 
unsatisfactory, amounts to an approximate $5 \%$ reduction in unsatisfactory performance statewide.

A second way to assess the practical significance of lead policy is to investigate the extent to which reductions in lead gaps between high- and low-income communities yielded reductions in achievement gaps between those communities. Comparing by income and over time, I calculate that declines in the 1990s in the lead gap (measured as share of children with lead above $10 \mu \mathrm{g} / \mathrm{dL}$ ) reduced the achievement gap (measured as share of children scoring unsatisfactory) by 1.0 percentage point in the 2000s. This suggests that the benefits of lead reduction disproportionately benefited low income children, thereby slightly reducing inequality in academic outcomes.

A third way to understand these results is to compare the effects of lead policy with the effects of tax or spending policy that increases family income. Consider low income communities - what income increase would they need to be given to provide them as much performance improvement as they received from the lead decrease? (This is basically a version of equivalent variation.) Over the sample period, the share of children in low income communities with lead above $10 \mu \mathrm{g} / \mathrm{dL}$ dropped by 9.2 percentage points, from $11.9 \%$ to $2.7 \%$. Applying the regression results, this decline in lead would cause a drop of 1.9 percentage points in the share scoring unsatisfactory. To achieve this same improvement via a shift of the income profile of low income communities towards the income profile of middle income communities, that shift would have to close $22 \%$ of the gap between the low and middle income communities. Specifically, low income communities would need to experience an increase of $\$ 2200$ of percapita income, a decrease of 1.3 percentage points in poverty rate, and a decrease of 5.4 percentage points in the share of students who are low income. Accordingly, to get, without the decline in lead, the same test score performance that was seen at the end of the period, per-capita income would have had to go up by $15 \%$ for low income communities.

How significant are these effects in a practical sense? All of these assessments of benefits can be considered relative to government spending on lead policy, which in 
Massachusetts is currently less than $\$ 5$ million. ${ }^{31}$ Since this is several orders of magnitude smaller than education spending in Massachusetts, it would appear that spending on lead policy provides a comparatively high return. While a more extensive cost-benefit analysis is merited and will be done in future work, these initial calculations suggest that public health policy has slightly improved academic outcomes and reduced inequality. Indeed, given that the literature provides substantial evidence for larger marginal effects of lead below $10 \mu \mathrm{g} / \mathrm{dL}$, and that this paper's group-level analysis has difficulty identifying such effects, as well as the fact that other benefits such as reduced special education dollars are not yet accounted for, it is likely that the benefit-cost analysis is quite favorable relative to other policy interventions. ${ }^{32}$

\section{Conclusion}

Using comprehensive data on lead levels in the 1990s and test scores in the 2000s, this paper has investigated whether childhood lead levels are linked to academic performance in childhood. One motivation for this study was to assess any measurable societal-level effects of Massachusetts' strong public health policy. Another motivation was to seek additional evidence on the more general question of whether and how lead may affect children's development and life outcomes, and what that means for society.

The paper has shown a strong cross-sectional relationship between early childhood lead level and elementary-school test scores. Groups of children with higher childhood lead levels perform substantially worse on standardized tests in third and fourth grades. These results are greatly diminished with the introduction of controls for community and school characteristics, and results for group average lead levels and group average test scores are not robust to the inclusion of these controls for confounding characteristics. Analyses on other moments of the distributions, in particular the share of children with elevated blood lead and the share of

\footnotetext{
${ }^{31}$ In Fiscal Year 2011, spending of all government agencies in Massachusetts on lead reduction efforts totaled approximately $\$ 4$ million. Source: author's personal communication in May 2011 with Paul Hunter, Director of the Massachusetts Childhood Lead Poisoning Prevention Program, Department of Environmental Health, Massachusetts Department of Public Health.

32 See Muennig (2009) and Gould (2009) for comprehensive benefit-cost analyses of societal reductions in childhood lead levels to as low as a population average below $1 \mu \mathrm{g} / \mathrm{dL}$.
} 
children scoring unsatisfactory on the MCAS test, yield more substantial, significant, and robust results. Over the time period under consideration, reductions in lead have yielded a drop of 1 to 2 percentage points in the share of children scoring unsatisfactory on the MCAS test, a change equivalent to what would have resulted from a $\$ 1000-\$ 2000$ increase in income per capita. Continuing research will employ individual-level data to better identify these effects and will extend the analysis with a more comprehensive benefit-cost analysis of lead policy in the context of broader social policy.

In conclusion, by studying lead and academic performance in Massachusetts - a state that made great strides in reducing children's blood lead levels - this paper has confirmed not only that lead does adversely affect academic performance but also that the aggregate societal impact of aggressive public health policy to reduce lead can be sizeable. Indeed, this work suggests that dollars spent on public health policy have a high return relative to dollars spent on education policy. Consequently, policymakers concerned with improving academic outcomes may want to broaden their view, looking beyond traditional education policies to consider other environmental and public health policies that can have considerable impacts on children's cognitive and social development. These policies and their impacts are certainly of historical interest, but it would be a mistake to think they exist only in the past. Rather, they continue to provide compelling potential opportunities to leverage public health policy in ways that could provide substantial societal benefits in the future. 


\section{References}

Almond, Douglas and Janet Currie (2010). "Human Capital Development before Age Five." National Bureau of Economic Research Working Paper No. 15827.

Anyon, Jean (2005). "What 'Counts' as Educational Policy? Notes toward a New Paradigm." Harvard Educational Review 75(1): 65-88.

Bellinger David C. (2008). "Very Low Lead Exposures and Children's Neurodevelopment." Current Opinions in Pediatrics 20(2): 172-177. Available at http://www.ncbi.nlm.nih.gov/pubmed/18332714.

Berger, Noah and Jeff McLynch (2006). "Public School Funding in Massachusetts: Where We Are, What Has Changed, and Options Ahead." Massachusetts Budget and Policy Center, November 2006.

Berhane, Kiros, W. James Gauderman, Daniel O. Stram, Duncan C. Thomas (2004). “Statistical Issues in Studies of the Long-Term Effects of Air Pollution: The Southern California Children's Health Study." Statistical Science, 19(3): 414-434.

Canfield, R. L., C.R. Henderson, D. Cory-Slechta, C. Cox, T. Jusko, and B. Lanphear (2003). "Intellectual impairment in children with blood lead concentrations below $10 \mu \mathrm{g}$ per deciliter." New England Journal of Medicine 348: 1517-1526.

Card, David and A. Abigail Payne (2002). "School Finance Reform, the Distribution of School Spending, and the Distribution of Student Test Scores." Journal of Public Economics 83(1): 49-82.

Case, Anne and Christina Paxson (2010). "Causes and Consequences of Early Life Health." National Bureau of Economic Research Working Paper No. 15637.

Centers for Disease Control and Prevention, National Center for Environmental Health (2010). "Advisory Committee on Childhood Lead Poisoning Prevention Recommends a Work Group to Investigate Lowering Limits on Elevated Blood Lead Levels." Available at http://www.cdc.gov/nceh/lead/lower_blood levels.htm.

Chandramouli K, CD Steer, M Ellis, and AM Emond (2009). "Effects of Early Childhood Lead Exposure on Academic Performance and Behaviour of School Age Children." Archives of Disease in Childhood 94(11): 844-848.

Childhood Lead Poisoning Prevention Program, Massachusetts Department of Public Health (2004). "Massachusetts Strategic Plan to End Lead Poisoning by 2010."

Childhood Lead Poisoning Prevention Program, Massachusetts Department of Public Health (various years). "Screening and Incidence Statistics by Community." 
Childhood Lead Poisoning Prevention Program, Massachusetts Department of Public Health (2011). "Childhood Lead Poisoning Prevention Program Overview." Available at http://www.mass.gov/dph/clppp.

Downes, Thomas, Jeffrey Zabel, and Dana Ansel (2009). “Incomplete Grade: Massachusetts Education Reform at 15." MassINC Research Report.

Firebaugh, Glenn (1978). “A Rule for Inferring Individual-Level Relationships from Aggregate Data." American Sociological Review, 43(4): 557-572.

Gilbert, Steven G. and Bernard Weiss (2006). "A Rationale for Lowering the Blood Lead Action Level from 10 to 2 g/dL." Neurotoxicology 27: 693-701.

Gould, Elise (2009). "Childhood Lead Poisoning: Conservative Estimates of the Social and Economic Benefits of Lead Hazard Control." Environmental Health Perspectives 117(7): 1162-1167.

Hoxby, Caroline M. (2001). "All School Finance Equalizations Are Not Created Equal.” Quarterly Journal of Economics 116(4): 1189-1231.

Lanphear, Bruce, R. Hornung, et al. (2005). "Low-level environmental lead exposure and children's intellectual function: an international pooled analysis." Environmental Health Perspectives 113: 894-899.

Massachusetts Department of Elementary and Secondary Education (2011). "Massachusetts Comprehensive Assessment System Overview." Available at http://www.doe.mass.edu/mcas/overview.html.

Mielke, Howard W., C.R. Gonzales, PW Mielke (2011). “The Continuing Impact of Lead Dust on Children's Blood Lead." Environmental Research 111(8): 1164-72.

Mielke, Howard W., M.A. Laidlaw, C.R. Gonzales (2010). “Lead (Pb) Legacy from Vehicle Traffic in Eight California Urbanized Areas." Science of the Total Environment 408(19): 3965-75.

Miranda, M. L., Dohyeong Kim, Jerome Reiter, M. Alicia Overstreet Galeano and Pamela Maxson (2009). "Environmental Contributors to the Achievement Gap." NeuroToxicology 30: 1019-1024.

Miranda, Marie Lynn, Dohyeong Kim, Claire Osgood, and Douglas Hastings (2011). “The Impact of Early Childhood Lead Exposure on Educational Test Performance among Connecticut Schoolchildren, Phase 1 Report." Children's Environmental Health Initiative Research Report. Available at http://www.nicholas.duke.edu/cehi/about/news/leadct.htm.

Muennig, Peter (2009). “The Social Costs of Childhood Lead Exposure in the Post-Lead Regulation Era." Archives of Pediatric and Adolescent Medicine 163(9): 844-849.

Murray, Sheila E., William N. Evans, and Robert M. Schwab (1998). “Education Finance Reform and the Distribution of Education Resources." American Economic Review 88(4): 789-812. 
Reyes, Jessica W. (2007). “Environmental Policy as Social Policy? The Impact of Childhood Lead Exposure on Crime," B.E. Journal of Economic Analysis and Policy (Contributions) , 7:1.

Schnaas, L., S. Rothenberg, M. Flores, S. Martinez, C. Hernandez, E. Osorio, et al. (2006). "Reduced intellectual development in children with prenatal lead exposure." Environmental Health Perspectives 114: 791-797. 
Figure 1a. Rate of Blood Lead $\geq 10 \mu \mathrm{g} / \mathrm{dL}$ Massachusetts Children by Birth Year (1991-2008)

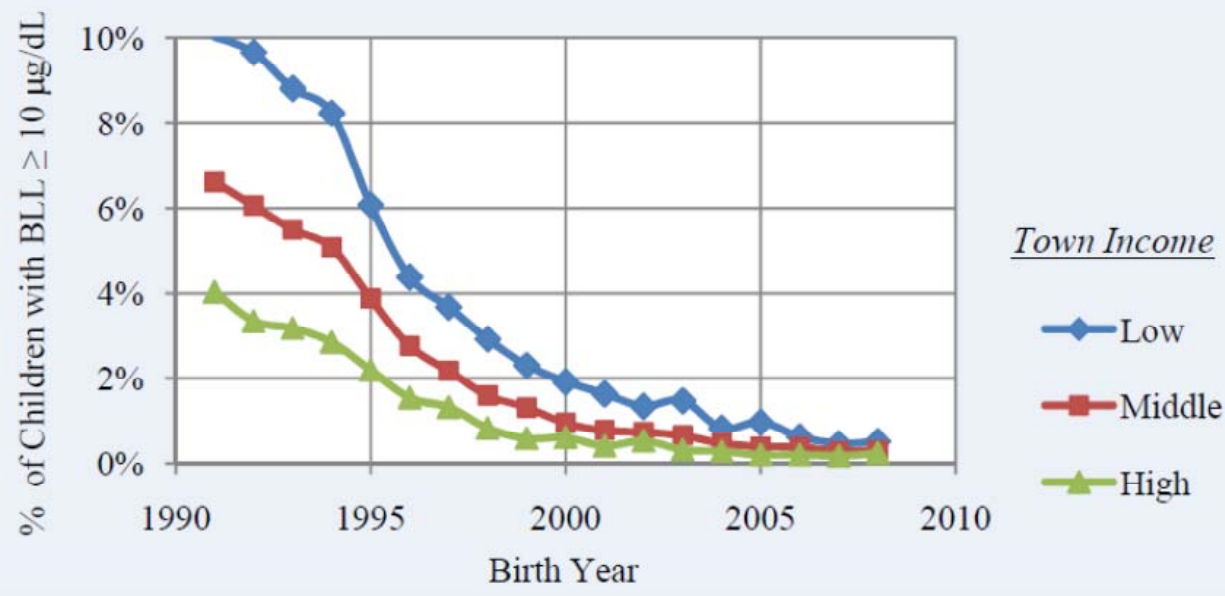

Notes. Income categories are based on town per-capita income in the year 2000 . "Low Income" includes towns with income in the bottom quartile $(<\$ 20,000)$, "Middle Income" includes towns in the middle two quartiles $(\$ 20,000-\$ 30,000)$. and "High Income" includes towns in the top quartile $(>\$ 30,000)$.

Figure 1b. Rate of Blood Lead $\geq 5 \mu \mathrm{g} / \mathrm{dL}$ Massachusetts Children by Birth Year (1991-2008)

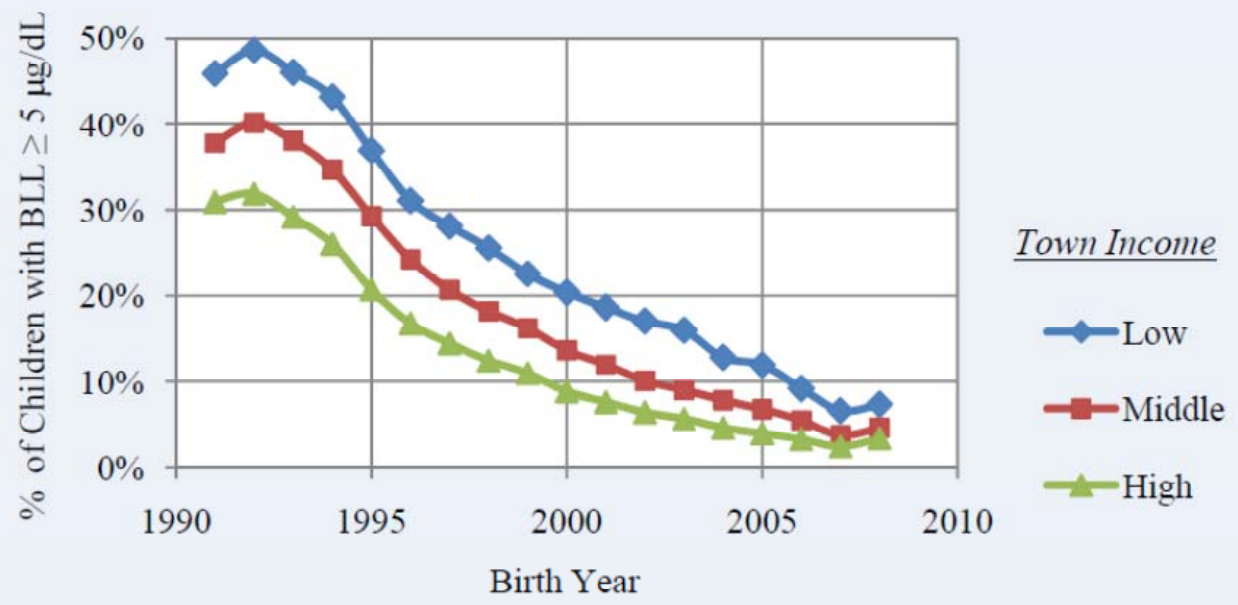

Notes. Income categories are based on town per-capita income in the year 2000 . "Low Income" includes towns with income in the bottom quartile $(<20,000)$. "Middle Income" includes towns in the middle two quartiles $(\$ 20,000-\$ 30,000)$. and "High Income" includes towns in the top quartile $(>\$ 30,000)$. 
Figure 2a. MCAS English Score vs. Childhood Lead For Fourth Grade, by Birth Year

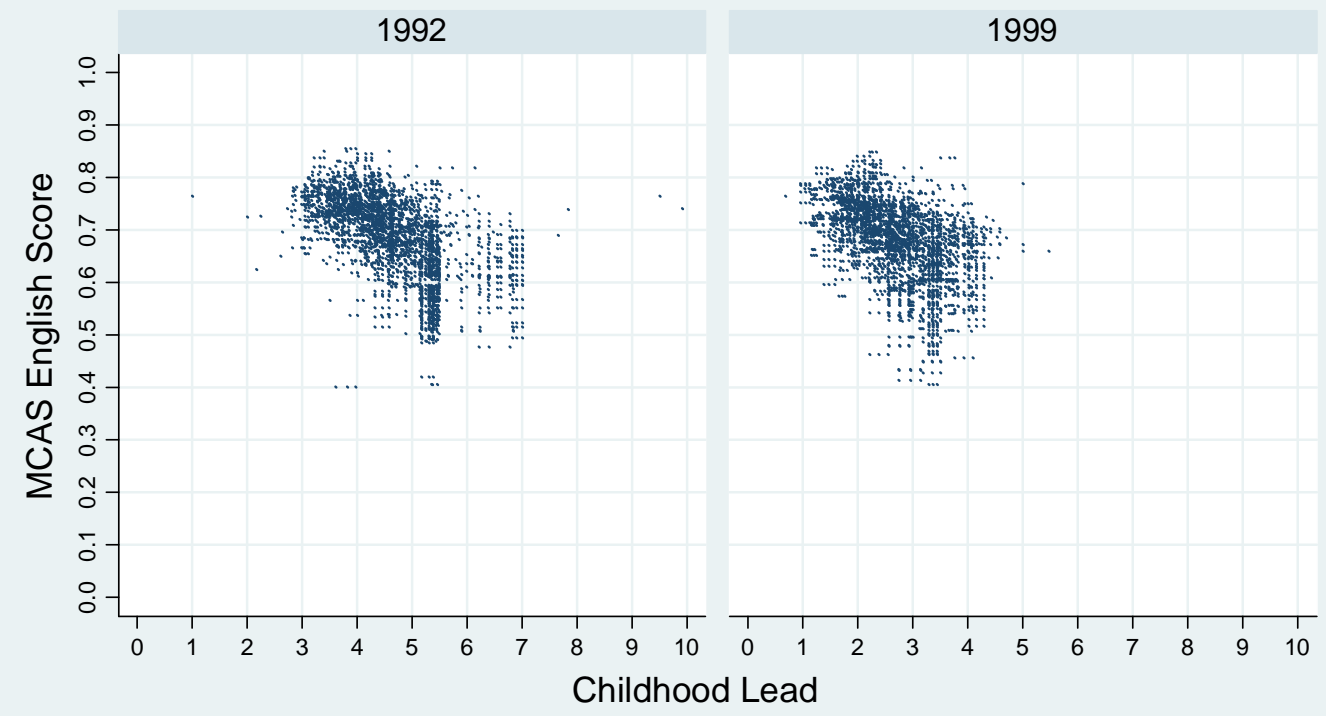

Notes: Author's calculations as described in text.

MCAS Score is the group average percent correct.

Childhood Lead is the group average in $\mathrm{mcg} / \mathrm{dl}$.

\section{Figure 2b. MCAS Math Score vs. Childhood Lead} For Fourth Grade, by Birth Year

1992

1999

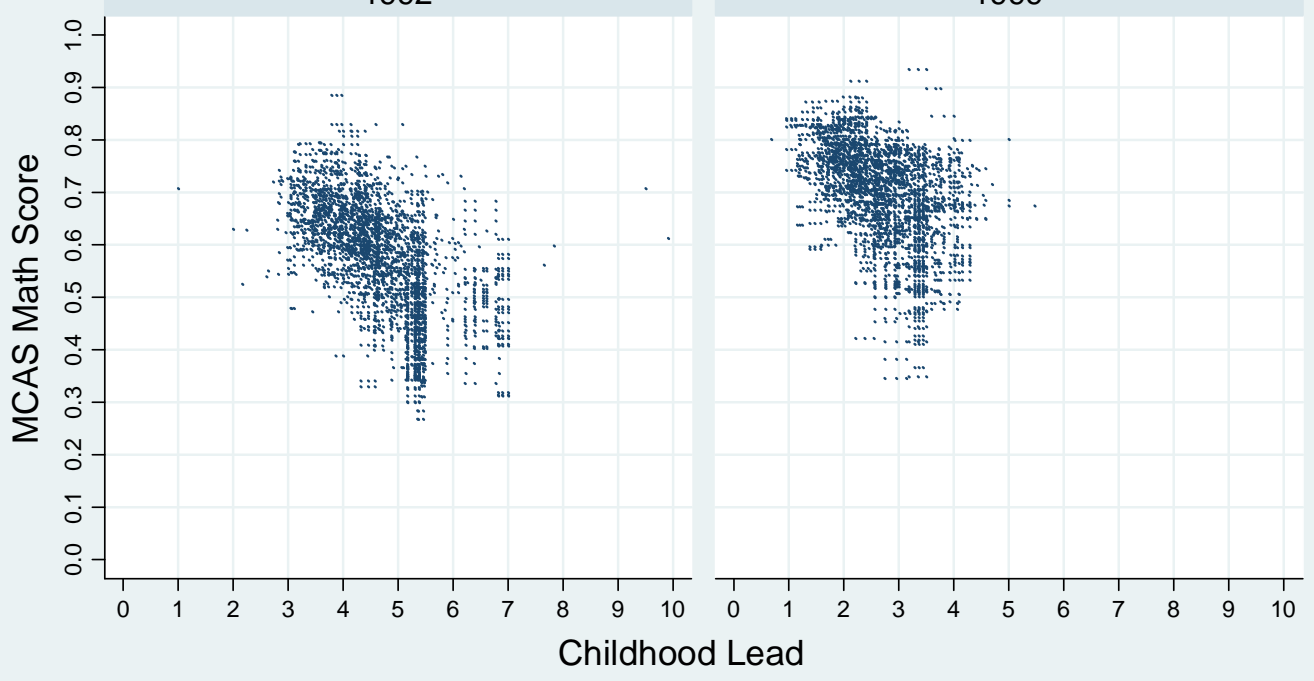

Notes: Author's calculations as described in text.

MCAS Score is the group average percent correct.

Childhood Lead is the group average in $\mathrm{mcg} / \mathrm{dl}$. 


\begin{tabular}{|c|c|c|c|c|c|c|c|c|c|c|c|c|c|}
\hline & \multicolumn{2}{|c|}{ Full Sample } & \multicolumn{5}{|c|}{ Early Cohorts ${ }^{\mathrm{a}}$ (Born 1991-1992) } & \multicolumn{6}{|c|}{ Late Cohorts $^{\mathrm{a}}$ (Born 1999-2000) } \\
\hline & & & \multicolumn{2}{|c|}{ All } & \multicolumn{2}{|c|}{$\begin{array}{c}\text { Low } \\
\text { Income }^{b}\end{array}$} & $\begin{array}{c}\text { High } \\
\text { Income }^{\mathrm{b}}\end{array}$ & \multicolumn{2}{|c|}{ All } & \multicolumn{2}{|c|}{$\begin{array}{c}\text { Low } \\
\text { Income }^{b}\end{array}$} & \multicolumn{2}{|c|}{$\begin{array}{c}\text { High } \\
\text { Income }^{b}\end{array}$} \\
\hline \multicolumn{14}{|l|}{ Lead Measures } \\
\hline Mean childhood lead $(\mu \mathrm{g} / \mathrm{dl})$ & 4.23 & $(1.00)$ & 5.20 & $(0.62)$ & 5.42 & $(0.59)$ & $4.10(0.63)$ & 3.14 & $(0.54)$ & 3.24 & $(0.55)$ & 2.25 & $(0.53)$ \\
\hline Share childhood lead 5-10 $\mu \mathrm{g} / \mathrm{dL}$ & 0.28 & $(0.09)$ & 0.36 & $(0.05)$ & 0.37 & $(0.04)$ & $0.28(0.06)$ & 0.17 & $(0.04)$ & 0.19 & $(0.04)$ & 0.10 & $(0.04)$ \\
\hline Share childhood lead > $10 \mu \mathrm{g} / \mathrm{dL}$ & 0.07 & $(0.04)$ & 0.11 & $(0.03)$ & 0.12 & $(0.04)$ & $0.05(0.03)$ & 0.03 & $(0.01)$ & 0.03 & $(0.01)$ & 0.01 & $(0.01)$ \\
\hline $\mathrm{d}$ m Share childhood lead $>20 \mu \mathrm{g} / \mathrm{dL}$ & 0.006 & $(0.00)$ & 0.010 & $(0.00)$ & 0.011 & $(0.00)$ & $0.004 \quad(0.00)$ & 0.002 & $(0.00)$ & 0.002 & $(0.00)$ & 0.001 & $(0.00)$ \\
\hline \multicolumn{14}{|l|}{ MCAS Scores: 3rd grade } \\
\hline English - average percentage correct & 0.76 & $(0.09)$ & 0.76 & $(0.09)$ & 0.70 & $(0.08)$ & $0.83(0.04)$ & 0.72 & $(0.08)$ & 0.66 & $(0.08)$ & 0.79 & $(0.04)$ \\
\hline English - share satisfactory & 0.61 & $(0.19)$ & 0.64 & $(0.20)$ & 0.50 & $(0.18)$ & $0.81(0.10)$ & 0.57 & $(0.19)$ & 0.43 & $(0.17)$ & 0.74 & $(0.10)$ \\
\hline Math - average percentage correct & 0.75 & $(0.09)$ & & & & & & 0.75 & $(0.09)$ & 0.69 & $(0.09)$ & 0.82 & $(0.05)$ \\
\hline Math - share satisfactory & 0.58 & $(0.19)$ & & & & & & 0.61 & $(0.19)$ & 0.48 & $(0.18)$ & 0.76 & $(0.11)$ \\
\hline \multicolumn{14}{|l|}{ MCAS Scores: 4th grade } \\
\hline English - percentage correct & 0.70 & $(0.07)$ & 0.69 & $(0.08)$ & 0.63 & $(0.06)$ & $0.75(0.05)$ & 0.70 & $(0.07)$ & 0.64 & $(0.07)$ & 0.76 & $(0.04)$ \\
\hline English - share satisfactory & 0.53 & $(0.21)$ & 0.52 & $(0.21)$ & 0.36 & $(0.16)$ & $0.71 \quad(0.13)$ & 0.51 & $(0.21)$ & 0.35 & $(0.16)$ & 0.70 & $(0.13)$ \\
\hline Math - percentage correct & 0.66 & $(0.10)$ & 0.59 & $(0.10)$ & 0.52 & $(0.08)$ & $0.68 \quad(0.07)$ & 0.69 & $(0.09)$ & 0.63 & $(0.08)$ & 0.77 & $(0.05)$ \\
\hline Math - share satisfactory & 0.43 & $(0.20)$ & 0.37 & $(0.20)$ & 0.23 & $(0.14)$ & $0.56(0.15)$ & 0.49 & $(0.19)$ & 0.37 & $(0.16)$ & 0.66 & $(0.13)$ \\
\hline \multicolumn{14}{|l|}{ Town Characteristics } \\
\hline Population density (thousands per sq mile) & 3.78 & $(4.11)$ & 3.83 & $(4.13)$ & 4.05 & $(3.36)$ & 3.01 (3.80) & 3.87 & $(4.28)$ & 4.11 & $(3.49)$ & 2.93 & $(3.72)$ \\
\hline Poverty rate & 0.09 & $(0.07)$ & 0.08 & $(0.06)$ & 0.13 & $(0.05)$ & $0.03(0.02)$ & 0.10 & $(0.08)$ & 0.17 & $(0.07)$ & 0.04 & $(0.03)$ \\
\hline Income per capita (\$k year 2000) & 27.00 & $(17.71)$ & 28.12 & $(19.47)$ & 14.96 & $(2.98)$ & $51.96(26.81)$ & 27.96 & $(18.27)$ & 14.92 & $(3.33)$ & 50.32 & $(23.57)$ \\
\hline Share with $<$ high school education & 0.16 & $(0.10)$ & 0.16 & $(0.10)$ & 0.26 & $(0.09)$ & $0.06(0.02)$ & 0.15 & $(0.10)$ & 0.26 & $(0.09)$ & 0.06 & $(0.02)$ \\
\hline Share with BA or beyond & 0.33 & $(0.17)$ & 0.33 & $(0.17)$ & 0.17 & $(0.07)$ & $0.56(0.11)$ & 0.33 & $(0.17)$ & 0.17 & $(0.07)$ & 0.57 & $(0.11)$ \\
\hline \multicolumn{14}{|l|}{ School Characteristics } \\
\hline Share of students that are low income & 0.32 & $(0.30)$ & 0.31 & $(0.29)$ & 0.53 & $(0.25)$ & $0.07(0.12)$ & 0.34 & $(0.30)$ & 0.60 & $(0.25)$ & 0.08 & $(0.11)$ \\
\hline Expenditures per pupil (\$k year 2000) & 8.87 & $(2.10)$ & 7.50 & $(1.33)$ & 7.30 & $(0.78)$ & 7.85 (1.75) & 10.26 & $(2.10)$ & 10.02 & $(0.98)$ & 10.44 & $(2.74)$ \\
\hline Share of students that are Black & 0.09 & $(0.15)$ & 0.10 & $(0.16)$ & 0.11 & $(0.12)$ & $0.05(0.10)$ & 0.09 & $(0.14)$ & 0.10 & $(0.12)$ & 0.05 & $(0.09)$ \\
\hline Share of students that are Hispanic & 0.14 & $(0.20)$ & 0.12 & $(0.18)$ & 0.22 & $(0.23)$ & $0.02(0.04)$ & 0.16 & $(0.21)$ & 0.30 & $(0.26)$ & 0.04 & $(0.05)$ \\
\hline \multicolumn{14}{|l|}{ Sample sizes } \\
\hline Number of groups & 18,342 & & 4,263 & & 1,447 & & 997 & 3,927 & & 1,271 & & 951 & \\
\hline Average group size & 68.38 & $(24.20)$ & 68.63 & $(24.03)$ & 61.87 & $(25.46)$ & $73.22(20.01)$ & 66.80 & $(24.03)$ & 65.85 & $(25.90)$ & 67.67 & $(20.32)$ \\
\hline
\end{tabular}

Notes. Means are shown, with standard deviations in parentheses. Each observation is a school/town-cohort-birthyear group. Data sources as described in text: lead data from the Massachusetts Department of Public Health, test score data from the Massachusetts Department of Elementary and Secondary Education.

${ }^{a}$ Early cohorts are the 1991 and 1992 birth-year cohorts; late cohorts are the 1999 and 2000 birth-year cohorts. For 3rd grade test scores, the earliest cohort in the data is the 1992 cohort and the latest is the 2000 cohort. For 4th grade test scores, the earliest cohort in the data is the 1991 cohort and the latest is the 1999 cohort.

${ }^{b}$ Income categories are based on town per-capita income in the year 2000. "Low Income" includes towns with income in the bottom quartile (<\$20,000), "Middle Income" (not shown) includes towns in the middle two quartiles $(\$ 20,000-30,000)$, and "High Income" includes towns in the top quartile $(>\$ 30,000)$. 


\section{Table 2. Differences-in-Differences.}

\begin{tabular}{|c|c|c|c|}
\hline Outcome Measure & DD1 & & $D D 2^{a, c}$ \\
\hline \multicolumn{4}{|l|}{ Mean score on MCAS } \\
\hline 3rd grade English & $0.016 * *$ & $(0.007)$ & $0.029 * *(0.010)$ \\
\hline 4th grade English & 0.009 & $(0.006)$ & $(0.009)$ \\
\hline 4th grade Math & $0.031 * *$ & $(0.008)$ & $0.045 * *(0.124)$ \\
\hline \multicolumn{4}{|c|}{ Share Unsatisfactory on MCAS } \\
\hline 3rd grade English & -0.022 & $(0.016)$ & $-0.052 * *(0.022)$ \\
\hline 4th grade English & -0.025 & $(0.017)$ & -0.038 \\
\hline 4th grade Math & $-0.047 * *$ & $(0.016)$ & $-0.065 * *(0.027)$ \\
\hline
\end{tabular}

${ }^{\mathrm{a}}$ The sample is broken into Treatment and Control based on 1992-1999 changes in the share of the group with lead above $10 \mu \mathrm{g} / \mathrm{dl}$.

${ }^{\mathrm{b}}$ For $D D 1$ : treatment groups are those with above-average changes, control groups are those with below-average changes.

${ }^{\mathrm{c}}$ For $\mathrm{DD} 2$ : treatment groups are those with top-quartile changes, control groups are those with bottom-quartile changes.

Notes. Difference-in-difference estimates and standard errors calculated from means and standard errors of each group (before/after, control/treatment).

Significance is indicated by * for a p-value $<0.10$ and $* *$ for a p-value $<0.05$. 
Table 3. Regression of Group Average MCAS English Scores on Group Average Childhood Lead.

\begin{tabular}{|c|c|c|c|c|c|c|}
\hline & $\begin{array}{c}(1) \\
\text { Base }\end{array}$ & $\begin{array}{c}\text { (2) } \\
\text { Weighted }\end{array}$ & $\begin{array}{c}\text { (3) } \\
\text { Include } \\
\text { Year F.E. }\end{array}$ & $\begin{array}{c}(4) \\
\text { Include } \\
\text { Town } \\
\text { Chars }\end{array}$ & $\begin{array}{c}(5) \\
\text { Include } \\
\text { School } \\
\text { Chars }\end{array}$ & (6) \\
\hline \multicolumn{7}{|l|}{ Childhood Lead Measures } \\
\hline Mean Childhood Lead ( $\mu \mathrm{g} / \mathrm{dL})$ & $\begin{array}{c}-0.0258 * * * \\
(0.0011)\end{array}$ & $\begin{array}{c}-0.0275 * * * \\
(0.0011)\end{array}$ & $\begin{array}{c}-0.0551^{* * *} \\
(0.0021)\end{array}$ & $\begin{array}{c}-0.0070 * * * \\
(0.0018)\end{array}$ & $\begin{array}{c}-0.0059 * * * \\
(0.0015)\end{array}$ & $\begin{array}{l}-0.0012 \\
(0.0015)\end{array}$ \\
\hline \multicolumn{7}{|l|}{ Town Characteristics } \\
\hline Town population density & & & & $\begin{array}{c}-0.0038 * * * \\
(0.0005)\end{array}$ & & $\begin{array}{c}0.0007 \\
(0.0005)\end{array}$ \\
\hline Town poverty rate & & & & $\begin{array}{c}-0.4646 * * * \\
(0.0474)\end{array}$ & & $\begin{array}{c}0.1472 * * * \\
(0.0443)\end{array}$ \\
\hline Town income per capita (\$k) & & & & $\begin{array}{l}0.0004 * \\
(0.0002)\end{array}$ & & $\begin{array}{c}0.0007 * * * \\
(0.0002)\end{array}$ \\
\hline Town income per capita squared & & & & $\begin{array}{c}-0.0000 * \\
(0.0000)\end{array}$ & & $\begin{array}{c}-0.0000 * * * \\
(0.0000)\end{array}$ \\
\hline Share of town with $<$ high school education & & & & $\begin{array}{c}0.0005 \\
(0.0320)\end{array}$ & & $\begin{array}{l}-0.0054 \\
(0.0234)\end{array}$ \\
\hline Share of town with BA or beyond & & & & $\begin{array}{c}0.0980 * * * \\
(0.0181)\end{array}$ & & $\begin{array}{c}0.0599 * * * \\
(0.0132)\end{array}$ \\
\hline \multicolumn{7}{|l|}{ School Characteristics } \\
\hline School expenditures per pupil (\$k) & & & & & $\begin{array}{c}0.0026^{* * *} \\
(0.0007)\end{array}$ & $\begin{array}{c}-0.0029 * * * \\
(0.0007)\end{array}$ \\
\hline Share of students that are low income & & & & & $\begin{array}{c}-0.1621^{* * *} \\
(0.0084)\end{array}$ & $\begin{array}{c}-0.1370 * * * \\
(0.0105)\end{array}$ \\
\hline Share of students that are Black & & & & & $\begin{array}{c}-0.0528 * * * \\
(0.0114)\end{array}$ & $\begin{array}{c}-0.0842 * * * \\
(0.0121)\end{array}$ \\
\hline Share of students that are Hispanic & & & & & $\begin{array}{c}-0.0614^{* * *} \\
(0.0117)\end{array}$ & $\begin{array}{c}-0.0908 * * * \\
(0.0127)\end{array}$ \\
\hline Constant & $\begin{array}{c}0.8432 * * * \\
(0.0038)\end{array}$ & $\begin{array}{c}0.8480^{* * *} \\
(0.0038)\end{array}$ & $\begin{array}{c}0.9870 * * * \\
(0.0088)\end{array}$ & $\begin{array}{c}0.7842 * * * \\
(0.0101)\end{array}$ & $\begin{array}{c}0.8132 * * * \\
(0.0076)\end{array}$ & $\begin{array}{c}0.7800 * * * \\
(0.0084)\end{array}$ \\
\hline Year Fixed Effects & No & No & Yes & Yes & Yes & Yes \\
\hline
\end{tabular}

Notes. Regression on groups of 3rd and 4th grade students in Massachusetts, where groups are defined by school and birth cohort. Test scores from MCAS tests taken from 2001 to 2009. Lead distributions based on second highest lead measured in childhood by the Massachusetts Department of Public Health. Year dummies for year MCAS is taken included where shown. Observations are weighted by weights derived from number of children in the data group (truncated below at 10 and above at 100). Standard errors are Huber-White robust and clustered by school. Significance is indicated by $* * *$ for $\mathrm{p}<0.01$, ** for $\mathrm{p}<0.05$, and $*$ for $\mathrm{p}<0.10$. 
Table 4. Regression of Group Average MCAS Math Scores on Group Average Childhood Lead.

\begin{tabular}{|c|c|c|c|c|c|c|}
\hline & $\begin{array}{c}(1) \\
\text { Base }\end{array}$ & $\begin{array}{c}\text { (2) } \\
\text { Weighted }\end{array}$ & $\begin{array}{c}\text { (3) } \\
\text { Include } \\
\text { Year F.E. }\end{array}$ & $\begin{array}{c}(4) \\
\text { Include } \\
\text { Town } \\
\text { Chars } \\
\end{array}$ & $\begin{array}{c}\text { (5) } \\
\text { Include } \\
\text { School } \\
\text { Chars } \\
\end{array}$ & $\begin{array}{l}(6) \\
\text { Full }\end{array}$ \\
\hline \multicolumn{7}{|l|}{ Childhood Lead Measures } \\
\hline Mean Childhood Lead ( $\mu \mathrm{g} / \mathrm{dL})$ & $\begin{array}{c}-0.0605^{* * *} \\
(0.0016)\end{array}$ & $\begin{array}{c}-0.0627 * * * \\
(0.0015)\end{array}$ & $\begin{array}{c}-0.0650^{* * *} \\
(0.0025)\end{array}$ & $\begin{array}{c}-0.0098 * * * \\
(0.0026)\end{array}$ & $\begin{array}{c}-0.0087 * * * \\
(0.0023)\end{array}$ & $\begin{array}{l}-0.0013 \\
(0.0022)\end{array}$ \\
\hline \multicolumn{7}{|l|}{ Town Characteristics } \\
\hline Town population density & & & & $\begin{array}{c}-0.0039 * * * \\
(0.0007)\end{array}$ & & $\begin{array}{c}0.0017^{* *} \\
(0.0007)\end{array}$ \\
\hline Town poverty rate & & & & $\begin{array}{c}-0.4380^{* * *} \\
(0.0557)\end{array}$ & & $\begin{array}{c}0.2120 * * * \\
(0.0547)\end{array}$ \\
\hline Town income per capita (\$k) & & & & $\begin{array}{c}0.0010^{* * *} \\
(0.0003)\end{array}$ & & $\begin{array}{c}0.0012 * * * \\
(0.0002)\end{array}$ \\
\hline Town income per capita squared & & & & $\begin{array}{c}-0.0000 * * * \\
(0.0000)\end{array}$ & & $\begin{array}{c}-0.0000^{* * *} \\
(0.0000)\end{array}$ \\
\hline Share of town with $<$ high school education & & & & $\begin{array}{l}-0.0143 \\
(0.0393)\end{array}$ & & $\begin{array}{l}-0.0348 \\
(0.0319)\end{array}$ \\
\hline Share of town with BA or beyond & & & & $\begin{array}{c}0.1119 * * * \\
(0.0235)\end{array}$ & & $\begin{array}{c}0.0766 * * * \\
(0.0193)\end{array}$ \\
\hline \multicolumn{7}{|l|}{ School Characteristics } \\
\hline School expenditures per pupil (\$k) & & & & & $\begin{array}{c}0.0038^{* * *} \\
(0.0009)\end{array}$ & $\begin{array}{c}-0.0044^{* * *} \\
(0.0010)\end{array}$ \\
\hline Share of students that are low income & & & & & $\begin{array}{c}-0.1864 * * * \\
(0.0125)\end{array}$ & $\begin{array}{c}-0.1418^{* * *} \\
(0.0150)\end{array}$ \\
\hline Share of students that are Black & & & & & $\begin{array}{c}-0.0619 * * * \\
(0.0157)\end{array}$ & $\begin{array}{c}-0.1162 * * * \\
(0.0170)\end{array}$ \\
\hline Share of students that are Hispanic & & & & & $\begin{array}{c}-0.0532 * * * \\
(0.0170)\end{array}$ & $\begin{array}{c}-0.1021 * * * \\
(0.0172)\end{array}$ \\
\hline Constant & $\begin{array}{c}0.9168 * * * \\
(0.0044)\end{array}$ & $\begin{array}{c}0.9209^{* * *} * \\
(0.0043)\end{array}$ & $\begin{array}{c}0.9221^{* * *} \\
(0.0106)\end{array}$ & $\begin{array}{c}0.6824 * * * \\
(0.0129)\end{array}$ & $\begin{array}{c}0.7271^{* * *} \\
(0.0107)\end{array}$ & $\begin{array}{c}0.6797 * * * \\
(0.0115)\end{array}$ \\
\hline Year Fixed Effects & No & No & Yes & Yes & Yes & Yes \\
\hline
\end{tabular}

Notes. Regression on groups of 3rd and 4th grade students in Massachusetts, where groups are defined by school and birth cohort. Test scores from MCAS tests taken from 2001 to 2009. Lead distributions based on second highest lead measured in childhood by the Massachusetts Department of Public Health. Year dummies for year MCAS is taken included where shown. Observations are weighted by weights derived from number of children in the data group (truncated below at 10 and above at 100). Standard errors are Huber-White robust and clustered by school. Significance is indicated by $* * *$ for $\mathrm{p}<0.01,{ }^{* *}$ for $\mathrm{p}<0.05$, and $*$ for $\mathrm{p}<0.10$. 
Table 5. Regression of Share Unsatisfactory MCAS on Share Lead in Certain Ranges.

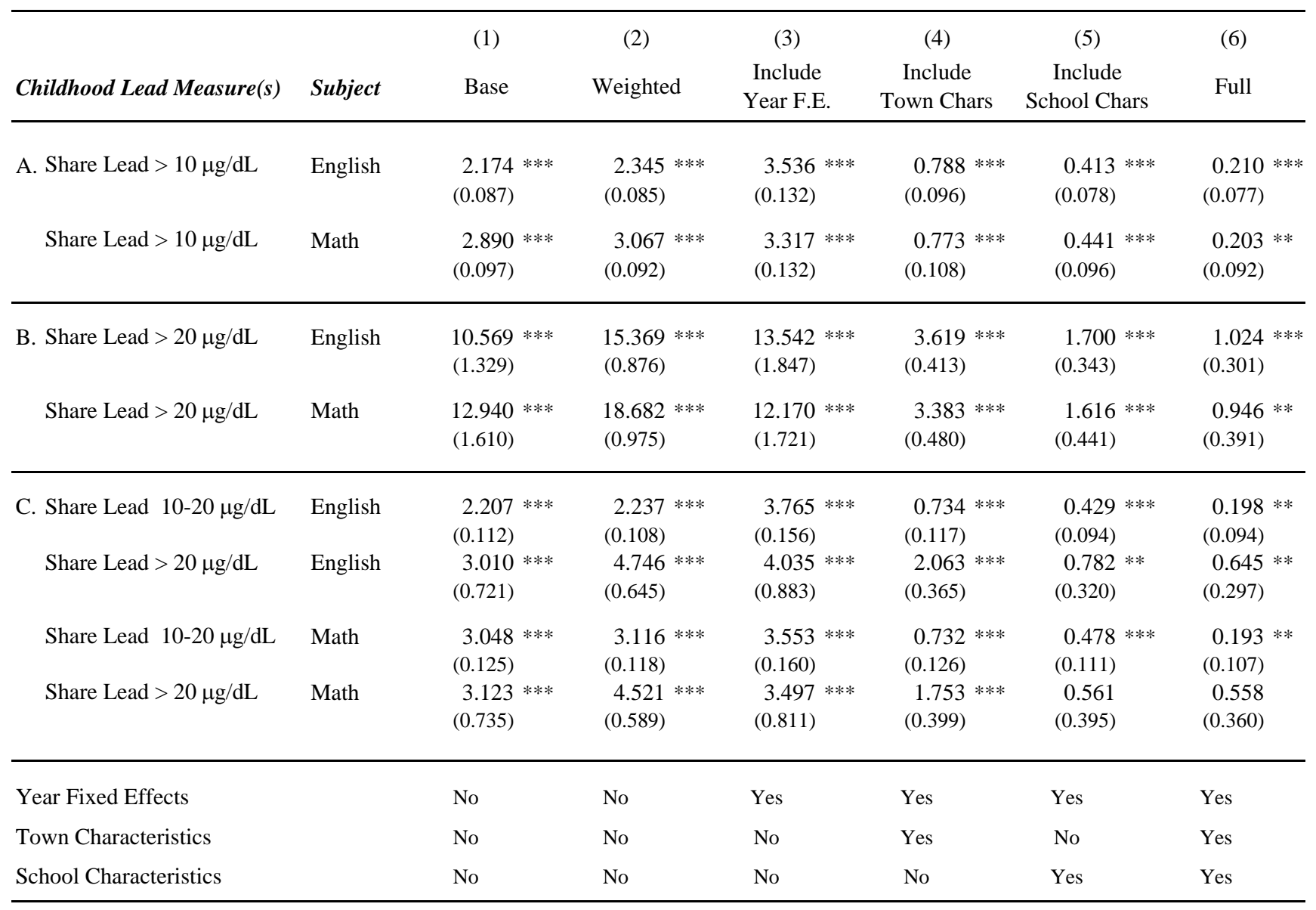

Notes. Regression on groups of 3rd and 4th grade students in Massachusetts, where groups are defined by school and birth cohort. Only coefficients on lead measures are shown. Test scores from MCAS tests taken from 2001 to 2009. Lead distributions based on second highest lead measured in childhood by the Massachusetts Department of Public Health. Year dummies for year MCAS is taken included where shown. Observations are weighted as described in the text. Standard errors are Huber-White robust and clustered by school. Significance is indicated by $* * *$ for $\mathrm{p}<0.01$, $* *$ for $\mathrm{p}<0.05$, and $*$ for $\mathrm{p}<0.10$. 
Table 6. Regression with Income Interactions of Share Unsatisfactory on Share Elevated Blood Lead.

\begin{tabular}{|c|c|c|c|c|}
\hline & $\begin{array}{c}\text { (1) } \\
\text { English } \\
\text { without } \\
\text { Town \& School } \\
\text { Chars }\end{array}$ & $\begin{array}{c}\text { (2) } \\
\text { English } \\
\text { with } \\
\text { Town \& School } \\
\text { Chars }\end{array}$ & $\begin{array}{c}\text { (3) } \\
\text { Math } \\
\text { without } \\
\text { Town \& School } \\
\text { Chars }\end{array}$ & $\begin{array}{c}\text { (4) } \\
\text { Math } \\
\text { with } \\
\text { Town \& School } \\
\text { Chars }\end{array}$ \\
\hline \multicolumn{5}{|l|}{ Childhood Lead Measures } \\
\hline Share Lead $>10 \mu \mathrm{g} / \mathrm{dL} \times$ Low Income Municipality & $\begin{array}{c}3.5432 * * * \\
(0.1222)\end{array}$ & $\begin{array}{l}0.1462 * \\
(0.0810)\end{array}$ & $\begin{array}{c}3.2726 * * * \\
(0.1223)\end{array}$ & $\begin{array}{c}0.1217 \\
(0.0931)\end{array}$ \\
\hline Share Lead $>10 \mu \mathrm{g} / \mathrm{dL} \times$ Middle Income Municipality & $\begin{array}{c}3.6805^{* * *} \\
(0.1721)\end{array}$ & $\begin{array}{c}0.4136^{* * *} \\
(0.1052)\end{array}$ & $\begin{array}{c}3.4379 * * * \\
(0.1661)\end{array}$ & $\begin{array}{c}0.5162 * * * \\
(0.1260)\end{array}$ \\
\hline Share Lead $>10 \mu \mathrm{g} / \mathrm{dL} \times$ High Income Municipality & $\begin{array}{l}0.5818 * \\
(0.3467)\end{array}$ & $\begin{array}{c}0.4048^{* * *} \\
(0.1469)\end{array}$ & $\begin{array}{l}-0.1373 \\
(0.4056)\end{array}$ & $\begin{array}{c}0.1600 \\
(0.2091)\end{array}$ \\
\hline \multicolumn{5}{|l|}{ Town Characteristics } \\
\hline Town population density & & $\begin{array}{c}-0.0023^{* *} \\
(0.0010)\end{array}$ & & $\begin{array}{c}-0.0033^{* * *} \\
(0.0013)\end{array}$ \\
\hline Town poverty rate & & $\begin{array}{c}-0.4031 * * * \\
(0.1012)\end{array}$ & & $\begin{array}{c}-0.4395 * * * \\
(0.1041)\end{array}$ \\
\hline Town income per capita (\$k) & & $\begin{array}{c}-0.0022 * * * \\
(0.0004)\end{array}$ & & $\begin{array}{c}-0.0027 * * * \\
(0.0005)\end{array}$ \\
\hline Town income per capita squared & & $\begin{array}{c}0.0000^{* * * *} \\
(0.0000)\end{array}$ & & $\begin{array}{c}0.0000^{* * * *} \\
(0.0000)\end{array}$ \\
\hline Share of town with $<$ high school education & & $\begin{array}{c}0.0781 \\
(0.0611)\end{array}$ & & $\begin{array}{c}0.0512 \\
(0.0627)\end{array}$ \\
\hline Share of town with BA or beyond & & $\begin{array}{c}-0.1845 * * * \\
(0.0335)\end{array}$ & & $\begin{array}{c}-0.2615^{* * *} \\
(0.0420)\end{array}$ \\
\hline \multicolumn{5}{|l|}{ School Characteristics } \\
\hline School expenditures per pupil (\$k) & & $\begin{array}{c}0.0092^{* * *} \\
(0.0017)\end{array}$ & & $\begin{array}{c}0.0126^{* * *} \\
(0.0020)\end{array}$ \\
\hline Share of students that are low income & & $\begin{array}{c}0.3811^{* * *} \\
(0.0234)\end{array}$ & & $\begin{array}{c}0.3022^{* * *} \\
(0.0278)\end{array}$ \\
\hline Share of students that are Black & & $\begin{array}{c}0.1542^{* * *} \\
(0.0266)\end{array}$ & & $\begin{array}{c}0.1530 * * * \\
(0.0309)\end{array}$ \\
\hline Share of students that are Hispanic & & $\begin{array}{c}0.1397^{* * * *} \\
(0.0244)\end{array}$ & & $\begin{array}{c}0.1145^{* * *} \\
(0.0284)\end{array}$ \\
\hline Constant & $\begin{array}{c}0.1832 * * * \\
(0.0083)\end{array}$ & $\begin{array}{c}0.3102^{* * *} \\
(0.0164)\end{array}$ & $\begin{array}{c}0.3367 * * * \\
(0.0100)\end{array}$ & $\begin{array}{c}0.4934 * * * \\
(0.0187)\end{array}$ \\
\hline Year Fixed Effects & Yes & Yes & Yes & Yes \\
\hline Town Characteristics & No & Yes & No & Yes \\
\hline School Characteristics & No & Yes & No & Yes \\
\hline
\end{tabular}

Notes. Regression on groups of 3rd and 4th grade students in Massachusetts, where groups are defined by school and birth cohort. Income categories are based on municipality per-capita income in the year 2000: "Low Income" includes municipalities with income in the bottom quartile $(<\sim \$ 20,000)$, "Middle Income" includes municipalities in the middle two quartiles $(\sim 20,000-30,000)$, and "High Income" includes municipalities in the top quartile ( $>\sim 30,000$ ). Test scores from MCAS tests taken from 2001 to 2009. Lead distributions based on second highest lead measured in childhood by the Massachusetts Department of Public Health. Year dummies for year MCAS is taken are included in all specifications. Observations are weighted by weights derived from number of children in the data group (truncated below at 10 and above at 100). Standard errors are Huber-White robust and clustered by school. Significance is indicated by *** for $\mathrm{p}<0.01$, ${ }^{* *}$ for $\mathrm{p}<0.05$, and $*$ for $\mathrm{p}<0.10$. 


\section{Appendix Table 1. Summary of Data Availability by Cohort.}

\begin{tabular}{|l|l|ll|ll|ll|lll|}
\hline $\begin{array}{l}\text { Cohort } \\
\text { called }\end{array}$ & Year will & Brad HS & Born... & & \multicolumn{2}{l|}{ Lead Measured } & \multicolumn{3}{l|}{ MCAS Taken } & \multicolumn{3}{l|}{ Number of Children } \\
\hline 1991 & 2009 & $9 / 1 / 90$ & $9 / 1 / 91$ & 1991 & 1998 & & 2001 & 77,456 & 79,362 & 88,176 \\
1992 & 2010 & $9 / 1 / 91$ & $9 / 1 / 92$ & 1992 & 1999 & 2001 & 2002 & 75,991 & 77,870 & 87,202 \\
1993 & 2011 & $9 / 1 / 92$ & $9 / 1 / 93$ & 1993 & 2000 & 2002 & 2003 & 73,341 & 75,996 & 84,627 \\
1994 & 2012 & $9 / 1 / 93$ & $9 / 1 / 94$ & 1994 & 2001 & 2003 & 2004 & 67,347 & 74,122 & 83,758 \\
1995 & 2013 & $9 / 1 / 94$ & $9 / 1 / 95$ & 1995 & 2002 & 2004 & 2005 & 66,519 & 73,381 & 81,562 \\
1996 & 2014 & $9 / 1 / 95$ & $9 / 1 / 96$ & 1996 & 2003 & 2005 & 2006 & 67,126 & 71,620 & 80,501 \\
1997 & 2015 & $9 / 1 / 96$ & $9 / 1 / 97$ & 1997 & 2004 & 2006 & 2007 & 66,780 & 71,023 & 80,321 \\
1998 & 2016 & $9 / 1 / 97$ & $9 / 1 / 98$ & 1998 & 2005 & 2007 & 2008 & 64,675 & 71,754 & 81,404 \\
1999 & 2017 & $9 / 1 / 98$ & $9 / 1 / 99$ & 1999 & 2006 & 2008 & 2009 & 63,258 & 70,942 & 80,864 \\
2000 & 2018 & $9 / 1 / 99$ & $9 / 1 / 00$ & 2000 & 2007 & 2009 & & 63,148 & 71,109 & 81,582 \\
\hline \hline
\end{tabular}

Notes. Data as described in the text. If year MCAS was taken is shown, that indicates that MCAS data is available for that cohort in that test year. The colors indicate availability of specific MCAS tests: blue indicates English Language Arts MCAS scores available; green indicates both English Language Arts and Mathematics MCAS scores available. Birth counts are from the Massachusetts Registry of Births. 


\section{Appendix Table 2. Regression of Group Share Unsatisfactory MCAS English Score on Group Share Childhood Lead above $10 \mu \mathrm{g} / \mathrm{dL}$.}

\begin{tabular}{|c|c|c|c|c|c|c|}
\hline & $\begin{array}{c}(1) \\
\text { Base }\end{array}$ & Weighted & $\begin{array}{c}\text { (3) } \\
\text { Include } \\
\text { Year F.E. }\end{array}$ & $\begin{array}{c}(4) \\
\text { Include } \\
\text { Town } \\
\text { Chars }\end{array}$ & $\begin{array}{c}(5) \\
\text { Include } \\
\text { School } \\
\text { Chars }\end{array}$ & $\begin{array}{l}(6) \\
\text { Full }\end{array}$ \\
\hline \multicolumn{7}{|l|}{ Childhood Lead Measures } \\
\hline Share Childhood Lead > $10 \mu \mathrm{g} / \mathrm{dL}$ & $\begin{array}{c}2.1739 * * * \\
(0.0873)\end{array}$ & $\begin{array}{c}2.3454^{* * *} \\
(0.0846)\end{array}$ & $\begin{array}{c}3.5361 * * * \\
(0.1320)\end{array}$ & $\begin{array}{l}0.7881 * * * \\
(0.0964)\end{array}$ & $\begin{array}{l}0.4134^{* * *} \\
(0.0781)\end{array}$ & $\begin{array}{c}0.2096 * * * \\
(0.0774)\end{array}$ \\
\hline \multicolumn{7}{|l|}{ Town Characteristics } \\
\hline Town population density & & & & $\begin{array}{l}0.0093 * * * \\
(0.0012)\end{array}$ & & $\begin{array}{l}-0.0016 \\
(0.0010)\end{array}$ \\
\hline Town poverty rate & & & & $\begin{array}{c}1.0078^{* * *} \\
(0.1011)\end{array}$ & & $\begin{array}{c}-0.4217 * * * \\
(0.1016)\end{array}$ \\
\hline Town income per capita (\$k) & & & & $\begin{array}{c}-0.0018^{* * *} \\
(0.0005)\end{array}$ & & $\begin{array}{c}-0.0021^{* * *} \\
(0.0004)\end{array}$ \\
\hline Town income per capita squared & & & & $\begin{array}{l}0.0000 * * * \\
(0.0000)\end{array}$ & & $\begin{array}{l}0.0000 * * * \\
(0.0000)\end{array}$ \\
\hline Share of town with $<$ high school education & & & & $\begin{array}{c}0.0180 \\
(0.0788)\end{array}$ & & $\begin{array}{c}0.0416 \\
(0.0581)\end{array}$ \\
\hline Share of town with BA or beyond & & & & $\begin{array}{c}-0.2712^{* * *} \\
(0.0438)\end{array}$ & & $\begin{array}{c}-0.1921 * * * \\
(0.0332)\end{array}$ \\
\hline \multicolumn{7}{|l|}{ School Characteristics } \\
\hline School expenditures per pupil (\$k) & & & & & $\begin{array}{c}-0.0067 * * * \\
(0.0017)\end{array}$ & $\begin{array}{c}0.0095 * * * \\
(0.0017)\end{array}$ \\
\hline Share of students that are low income & & & & & $\begin{array}{c}0.4946 * * * \\
(0.0180)\end{array}$ & $\begin{array}{c}0.3804 * * * \\
(0.0232)\end{array}$ \\
\hline Share of students that are Black & & & & & $\begin{array}{l}0.0577 * * \\
(0.0250)\end{array}$ & $\begin{array}{c}0.1637 * * * \\
(0.0265)\end{array}$ \\
\hline Share of students that are Hispanic & & & & & $\begin{array}{l}0.0413 * \\
(0.0232)\end{array}$ & $\begin{array}{c}0.1402 * * * \\
(0.0244)\end{array}$ \\
\hline Constant & $\begin{array}{c}0.3170^{* * *} \\
(0.0052)\end{array}$ & $\begin{array}{c}0.3116^{* * *} \\
(0.0053)\end{array}$ & $\begin{array}{c}0.1582^{* * *} \\
(0.0085)\end{array}$ & $\begin{array}{c}0.3595^{* * *} \\
(0.0165)\end{array}$ & $\begin{array}{c}0.2598^{* * *} \\
(0.0133)\end{array}$ & $\begin{array}{c}0.3183^{* * *} \\
(0.0154)\end{array}$ \\
\hline Year Fixed Effects & No & No & Yes & Yes & Yes & Yes \\
\hline
\end{tabular}

Notes. Regression on groups of 3rd and 4th grade students in Massachusetts, where groups are defined by school and birth cohort. Test scores from MCAS tests taken from 2001 to 2009. Lead distributions based on second highest lead measured in childhood by the Massachusetts Department of Public Health. Year dummies for year MCAS is taken included where shown. Observations are weighted by weights derived from number of children in the data group (truncated below at 10 and above at 100). Standard errors are Huber-White robust and clustered by school. Significance is indicated by $* * *$ for $\mathrm{p}<0.01$, $* *$ for $\mathrm{p}<0.05$, and $*$ for $\mathrm{p}<0.10$. 


\section{Appendix Table 3. Regression of Group Share Unsatisfactory MCAS Math Score on Group Share Childhood Lead above $10 \mu \mathrm{g} / \mathrm{dL}$.}

\begin{tabular}{|c|c|c|c|c|c|c|}
\hline & $\begin{array}{c}(1) \\
\text { Base }\end{array}$ & Weighted & $\begin{array}{c}\text { (3) } \\
\text { Include } \\
\text { Year F.E. }\end{array}$ & $\begin{array}{c}(4) \\
\text { Include } \\
\text { Town } \\
\text { Chars }\end{array}$ & $\begin{array}{c}(5) \\
\text { Include } \\
\text { School } \\
\text { Chars }\end{array}$ & $\begin{array}{l}(6) \\
\text { Full }\end{array}$ \\
\hline \multicolumn{7}{|l|}{ Childhood Lead Measures } \\
\hline Share Childhood Lead > $10 \mu \mathrm{g} / \mathrm{dL}$ & $\begin{array}{c}2.8899 * * * \\
(0.0973)\end{array}$ & $\begin{array}{c}3.0666 * * * \\
(0.0923)\end{array}$ & $\begin{array}{c}3.3172 * * * \\
(0.1316)\end{array}$ & $\begin{array}{l}0.7732 * * * \\
(0.1082)\end{array}$ & $\begin{array}{c}0.4407 * * * \\
(0.0958)\end{array}$ & $\begin{array}{c}0.2030 * * \\
(0.0918)\end{array}$ \\
\hline \multicolumn{7}{|l|}{ Town Characteristics } \\
\hline Town population density & & & & $\begin{array}{l}0.0081 * * * \\
(0.0013)\end{array}$ & & $\begin{array}{l}-0.0024^{*} \\
(0.0012)\end{array}$ \\
\hline Town poverty rate & & & & $\begin{array}{l}0.7127 * * * \\
(0.0948)\end{array}$ & & $\begin{array}{c}-0.4627 * * * \\
(0.1041)\end{array}$ \\
\hline Town income per capita (\$k) & & & & $\begin{array}{c}-0.0025^{* * *} \\
(0.0006)\end{array}$ & & $\begin{array}{c}-0.0026 * * * \\
(0.0005)\end{array}$ \\
\hline Town income per capita squared & & & & $\begin{array}{l}0.0000 * * * \\
(0.0000)\end{array}$ & & $\begin{array}{l}0.0000 * * * \\
(0.0000)\end{array}$ \\
\hline Share of town with $<$ high school education & & & & $\begin{array}{l}-0.0429 \\
(0.0758)\end{array}$ & & $\begin{array}{c}0.0001 \\
(0.0623)\end{array}$ \\
\hline Share of town with BA or beyond & & & & $\begin{array}{c}-0.3229 * * * \\
(0.0477)\end{array}$ & & $\begin{array}{c}-0.2809 * * * \\
(0.0421)\end{array}$ \\
\hline \multicolumn{7}{|l|}{ School Characteristics } \\
\hline School expenditures per pupil (\$k) & & & & & $\begin{array}{c}-0.0080 * * * \\
(0.0020)\end{array}$ & $\begin{array}{c}0.0128^{* * *} \\
(0.0020)\end{array}$ \\
\hline Share of students that are low income & & & & & $\begin{array}{l}0.4644^{* * *} \\
(0.0222)\end{array}$ & $\begin{array}{c}0.3024 * * * \\
(0.0276)\end{array}$ \\
\hline Share of students that are Black & & & & & $\begin{array}{c}0.0306 \\
(0.0283)\end{array}$ & $\begin{array}{c}0.1675^{* * *} \\
(0.0305)\end{array}$ \\
\hline Share of students that are Hispanic & & & & & $\begin{array}{l}-0.0184 \\
(0.0281)\end{array}$ & $\begin{array}{c}0.1156^{* * *} \\
(0.0282)\end{array}$ \\
\hline Constant & $\begin{array}{c}0.3782^{* * *} \\
(0.0054)\end{array}$ & $\begin{array}{c}0.3744 * * * \\
(0.0055)\end{array}$ & $\begin{array}{c}0.3049 * * * \\
(0.0101)\end{array}$ & $\begin{array}{c}0.5649 * * * \\
(0.0174)\end{array}$ & $\begin{array}{c}0.4193^{* * *} \\
(0.0159)\end{array}$ & $\begin{array}{c}0.5078 * * * \\
(0.0178)\end{array}$ \\
\hline Year Fixed Effects & No & No & Yes & Yes & Yes & Yes \\
\hline
\end{tabular}

Notes. Regression on groups of 3rd and 4th grade students in Massachusetts, where groups are defined by school and birth cohort. Test scores from MCAS tests taken from 2001 to 2009. Lead distributions based on second highest lead measured in childhood by the Massachusetts Department of Public Health. Year dummies for year MCAS is taken included where shown. Observations are weighted by weights derived from number of children in the data group (truncated below at 10 and above at 100). Standard errors are Huber-White robust and clustered by school. Significance is indicated by $* * *$ for $\mathrm{p}<0.01$, $* *$ for $\mathrm{p}<0.05$, and $*$ for $\mathrm{p}<0.10$. 


\section{Appendix A: Massachusetts General Laws Regarding Lead Exposure, Lead Poisoning, and Lead Screening}

Available thru WestLaw, LexisNexis, or at http://www.lawlib.state.ma.us/subject/about/lead.html

\section{MGL 111 s. 189A-199B Lead Poisoning Prevention \& Control}

Excerpts are below.

\section{MGL 111 s. 192 Educational and Publicity Program}

Section 192. The director shall institute an educational and publicity program, in order to inform the general public, and particularly parents of children residing in areas of significant exposure to sources of lead poisoning; teachers, social workers and other human service personnel; owners of residential property, particularly property constructed previous to the year nineteen hundred and forty-five; and health services personnel, and particularly interns, residents and other intake personnel at major hospitals, of the dangers, frequency, and sources of lead poisoning, and the methods of preventing such poisoning.

\section{MGL 111 s. 193 Early Identification Program; Examination and Reports}

Section 193. The director shall establish a program for early identification of cases of lead poisoning. Such program shall systematically screen all children under six years of age for the presence of lead poisoning. The director shall, after consultation with recognized professional medical groups and such other sources as he deems appropriate, promulgate regulations establishing (1) the means by which and the intervals at which children under six years of age shall be screened for lead poisoning and (2) guidelines for the medical follow-up of children found to be lead poisoned. The director may also prescribe a screening schedule for pregnant women, children six years of age and older including such children who exhibit pica, and persons whose cognitive development is delayed or retarded if he finds such additional screening to be medically warranted. Such program shall employ, to the extent possible, residents of the areas in which screening and examinations are conducted, which residents shall not be subject to the provisions of chapter thirty-one, unless required as a condition for receipt of federal funds, or section nine A of chapter thirty.

Such identification program shall, to the extent that all children residing in the commonwealth are not systematically screened, give priority in screenings to children residing, or who have recently resided, in areas where significant numbers of lead poisoning cases have recently been reported or where other reliable evidence indicates that significant numbers of lead poisoning cases may be found.

When the director is informed of a case of lead poisoning pursuant to section one hundred and ninety-one, or otherwise, he shall cause to have screened all other children under six years of age, and such other children as he may find advisable to screen, residing or recently residing in the household of the victim, unless the parents of such 
child object to said screening because it conflicts with their religious beliefs and practices. The results of such screenings shall be reported to the director, to the person or agency reporting the original case pursuant to section one hundred and ninety-one, and to such other persons or agencies as the director deems advisable.

The director shall maintain comprehensive records of all screenings conducted pursuant to this section. Such records shall be geographically indexed in order to determine the location of areas of relatively high incidence of lead poisoning. Such records shall be public records, subject to the provision of section one hundred and ninety-one relating to the names of screened individuals. A summary of the results of all screenings conducted pursuant to this section shall be released quarterly, or more frequently if the director so determines, to all interested parties.

All cases or probable cases of lead poisoning, as defined by regulation by the director, found in the course of screenings conducted pursuant to this section shall be reported immediately to the affected individual, to his parent or legal guardian if he is a minor, and to the director. The director shall inform such persons or agencies as he deems advisable of the existence of such case or probable case, subject to the provision of section one hundred and ninety-one relating to the names of individuals.

MGL 111 s. 197 (a) Duty of residential premises owners; interim control measures; removal or cover of offending paint, soil, or material.

Section 197. (a) Whenever a child under six years of age resides in any premises in which any paint, plaster or other accessible structural material contains dangerous levels of lead, the owner shall abate or contain said paint, plaster or other accessible structural materials in accordance with the requirements of subsection (b) or (c). Except as provided in section one hundred and ninety-seven $\mathrm{D}$, whenever any such premises containing said dangerous levels of lead undergoes a change of ownership and as a result a child under six years of age will become or will continue to be a resident therein, the new owner shall have ninety days to contain or abate said paint, plaster or other accessible structural material as required by this section, so as to make the premises in compliance with the provisions of sections one hundred and eighty-nine A to one hundred and ninety-nine B, inclusive.

\section{MGL 112 s. 12BB Mandatory Screening by Physicians of Preschool Children}

Section 12BB. Each physician duly registered under the provisions of section two, two A, nine, nine A, or nine B shall screen patients for lead poisoning at the intervals and using the methods specified in the regulations adopted pursuant to section one hundred and ninety-three of chapter one hundred and eleven. Each licensed, registered or approved health care facility serving children under six years of age, including but not limited to hospitals and clinics licensed under the provisions of section fifty-one of chapter one hundred and eleven and health maintenance organizations approved under the provisions of chapter one hundred and seventy-six $G$, shall take appropriate steps to ensure that their patients receive such lead poisoning screening. 


\section{Appendix B: Massachusetts Comprehensive Assessment System Performance Level Definitions}

Reproduced from: "Massachusetts Comprehensive Assessment System Overview," Massachusetts Department of Elementary and Secondary Education.

Available at http://www.doe.mass.edu/mcas/overview.html.

Student results on MCAS tests are reported according to the following performance levels:

- Grade 3 tests: $\quad$ Above Proficient, Proficient, Needs Improvement, Warning

- Grades 4-8 tests: Advanced, Proficient, Needs Improvement, Warning

- Grade 10 tests: Advanced, Proficient, Needs Improvement, Failing

The performance level definitions below, which apply across subject areas and grade levels, are used as a basis for determining the minimum score for each of the performance levels on each of the MCAS tests. ... The general and content-specific definitions are meant to help teachers, students, parents, and others understand the meaning of the MCAS results.

General Performance Level Definitions

- Advanced (Grades 4-10): Students at this level demonstrate a comprehensive and in-depth understanding of rigorous subject matter, and provide sophisticated solutions to complex problems.

- Above Proficient (Grade 3): Students at this level demonstrate mastery of challenging subject matter and construct solutions to challenging problems.

- Proficient (Grades 3-10): Students at this level demonstrate a solid understanding of challenging subject matter and solve a wide variety of problems.

- Needs Improvement (Grades 3-10): Students at this level demonstrate a partial understanding of subject matter and solve some simple problems.

- Warning (Grades 3-8)/Failing (Grade 10): Students at this level demonstrate a minimal understanding of subject matter and do not solve simple problems. 